Discussion Paper No. 784

\title{
ORGANIZATION ADJUSTMENTS, JOB TRAINING AND PRODUCTIVITY: EVIDENCE FROM JAPANESE AUTOMOBILE MAKERS
}

\author{
Kenn Ariga \\ Masako Kurosawa \\ Fumio Ohtake \\ Masaru Sasaki \\ Shoko Yamane
}

July 2010

The Institute of Social and Economic Research

Osaka University

6-1 Mihogaoka, Ibaraki, Osaka 567-0047, Japan 


\title{
Organization Adjustments, Job Training and Productivity: Evidence from Japanese Automobile Makers
}

\author{
Kenn Ariga Masako Kurosawa Fumio Ohtake \\ Kyoto University GRIPS Osaka University \\ $\begin{array}{cc}\text { Masaru Sasaki* }^{*} & \text { Shoko Yamane } \\ \text { Osaka University } & \text { Osaka University }\end{array}$
}

July 15, 2010

\begin{abstract}
This paper considers the demand for job training and its interaction with organization adjustments through rotation within a team and relocation across teams in response to demand and supply shocks. The analysis includes estimations of determinants of on-thejob training, and of how much such training contributes to improvements in individual productivity. We employ original assembler survey data from two Japanese automobile makers. We also investigate effects of the characteristics of workplace practices, including the behavior of foremen, on the incentives for individual assemblers to seek job training and productivity improvements.
\end{abstract}

Key words: Job training, productivity improvement, relocation, rotation, workplace practices

JEL Classification: J24, M53

\footnotetext{
* Corresponding to: ISER, Osaka University, 6-1 Mihogaoka, Ibaraki, Osaka, 567-0047, Japan. Email: sasaki@econ.osaka-u.ac.jp. The authors are grateful to the participants in the 2009 TransPacific Labor Seminar at the Japan Institute for Labour Policy and Trainings (JILPT) Kasumigaseki Office, Tokyo, FESAM 2009, the 2009 Japanese Economic Association Meeting for their valuable comments. We also thank the personnel departments of the two automobile makers that helped us collect the data and allowed us to use it for this research. Any errors are of course our responsibility.
} 


\section{Introduction}

Does job training really contribute to improvements in productivity? Why do even veteran workers keep receiving job training? Is job training useful for accomplishing multiple tasks in response to unexpected shocks? Using original survey data from the manufacturing establishments of two Japanese automobile firms, the purpose of this paper is threefold. First, we investigate the continuous provision of job training, including for veteran assemblers when each task in the assembly line is simple and easily learnt. If this is the case, why is continuous job training necessary? Second, we estimate the determinants of the extent and intensity of firm-level training such as onthe-job training (OJT). Finally, we consider the impact of OJT and workplace environments and practices on an individual assembler's productivity. It is, of course, imperative to measure the costs and benefits of OJT from the viewpoint of the firm's human resources management strategy, to establish whether and by how much individual productivity improves through the provision of job training. We estimate the effect of job training on productivity changes at the individual level using original data from selected establishments of two Japanese automobile makers.

The main contribution of this paper is the analysis of original survey data collected from assemblers and foremen in representative Japanese automobile makers on their subjective assessment of productivity improvements. These data allow us to provide a direct link between the intensity of OJT and productivity improvements. Because it is difficult to measure objectively the extent and intensity of OJT and productivity improvements, we use subjectively assessed measures for those variables, even though some measurement error may be involved. To support its appropriateness as a measure of productivity improvement, we alternatively employ the change in the number of operational tasks that assemblers can perform satisfactorily as evaluated by their foreman. According to the factory director interviewed, assemblers usually assessed their own productivity improvements when responding to the survey questionnaire in terms of an increase in the number of operational tasks they could perform. However, the data on operational tasks were available only from a single automaker in the third wave of the survey. Nevertheless, while the original data have some disadvantages, they also have several redeeming qualities. For instance, many economists and business academics have long been suspicious that older workers with long tenure in Japanese automakers remain engaged in job training, despite the fact that the operations they usually perform are simple and do not take a long time to learn. ${ }^{1}$ Using our original data, we are able to look inside the black box that until now concealed the effect of OJT on productivity.

Another distinguishing feature of this study is that it explores how both the characteristics of teams and individuals (including the workplace environment and workplace practices) affect the determinants of job training and the extent of productivity improvements (if any). Changes in the workload and assembly line speed responded to by foremen are included in the characteristics of teams, and these capture

\footnotetext{
${ }^{1}$ A major alternative reason to provide old and veteran assemblers with training is to develop talent that can handle "unusual operations" (Koike 1994 2002). The depth of the skill (as opposed to the width) is such that the highest (deepest) skill involves capability to deal with accidents, machine malfunctions that need be resolved quickly on the spot. The "depth" enhances the team productivity by minimizing the delay or stoppage of operation after the incidence. Unlike multiskilling, it seems there is a need for some of the assemblers in the team to have this capability.
} 
the extent and intensity of any demand shocks. In addition, the proposed Kaizen drafts for job efficiency improvements and the number of quality control (QC) meetings are also studied, and these capture the extent and intensity of any supply shocks. ${ }^{2}$ We predict that frequent demand and supply shocks lead to assignment changes for assemblers through rotation within their own team and/or relocation across teams. This provides the ongoing demand for job training for assemblers, even veteran assemblers, so they can adjust to the environmental changes. Importantly, while the literature includes the effects of individual characteristics on the intensity of job training, our study also focuses on the interaction between individual and team characteristics.

There is some evidence suggesting that job training is highly selective, at least in OECD countries other than Japan where no systematic study yet exists. Using Thai data, Ariga and Brunello (2006) found that while off-the-training (OffJT) and education were complements, OJT and education were substitutes. In general, training is most intensive in the early stages of an assembler's career and experience. Some studies found very high returns to job training, but these were likely to suffer from selection bias. In fact, and as pointed out by Leuven and Oosterbeek (2005), past studies have relied on data collected from highly heterogeneous workplaces that they likely fail to control. Using original data from the manufacturing establishments of two Japanese automobile makers, we investigate the types of job training provided in the various career stages. Further, as our unique survey includes assemblers within the same establishment, we do not potentially suffer from the selection bias found elsewhere.

The paper is organized as follows. The next section discusses how an automobile establishment adjusts to demand and supply shocks, why organization adjustments are necessary, and why organization adjustments frequently occur in the Japanese manufacturing sector. Section 3 explains the data, followed by descriptive statistics for job training and subjectively and objectively assessed productivity in Section 4. Section 5 discusses the econometric methodology and Section 6 includes the results. Section 7 shows a simple simulation to discuss the cost and benefit of internal labor adjustments. The final section provides some concluding remarks and future research directions.

\section{Organization Adjustments in Response to Demand and Supply Shocks}

Why is job training continuously provided, even for veteran assemblers, despite tasks in the assembly line being simple and easy to learn? This subsection explains the linkages between unexpected productivity shocks, the provision of job training, and productivity improvements. Figure 1 depicts these linkages.

We predict that shocks from the demand or supply side induce organization adjustments in assembly lines, thereby increasing the demand for training. We here focus attention on two types of organization adjustments: rotation within the same team and relocation across teams. Rotation within the same team is defined as a transfer between production operations in the same team; on the other hand, relocation is defined as a broader transfer between teams but within the same establishment. ${ }^{3}$

\footnotetext{
${ }^{2}$ Kaizen means operational improvement in Japanese. In many manufacturing sectors, including automobile sector, assemblers are encouraged to suggest drafts to improve efficiency in their assembly line.

${ }^{3}$ Assemblers usually are not transferred across establishments, but foremen are often instructed to relocate to a different establishment.
} 
Hildreth and Ohtake (1998) also deal with labor demand adjustment through organization adjustments, using the establishment-level data from an automobile maker. They find that this automobile maker uses two methods to adjust labor demand; the first method is a long-term transfer indicating relocation of assemblers across establishments; the second method is a short-term transfer between assembly lines and between production and nonproduction sectors as well as between establishments. The short-term transfer allows the automobile maker to cope with demand fluctuation, showing that it can adjust employment quickly and flexibly, contrary to the common belief that labor demand adjustment is slower in Japan than in Western countries. As this paper emphasizes within-establishment relocation, it is close to the short-term transfer model in Hildreth and Ohtake (1998).

Why is it worthwhile to undertake organization adjustments? There are three reasons to support them. The first is that assemblers rotate within the same teams or are relocated to a different team to cope with demand shocks, including the business cycle, seasonal adjustments and establishment-level shocks. Demand shocks occur regularly for a host of different reasons. Organization adjustments occur more or less continuously, as one model is experiencing growing demand, whereas others' market share is declining. ${ }^{4}$ Fads concerning choice of color are also evident in Japan. There was a time when every new car was white, and then black was the most popular color, then light blue, shiny pink, and so on. More (fewer) assemblers are located in the assembly line to cope with the increased (decreased) workload. Flexible organization adjustments reduce the number of redundant assemblers and the surplus of human resource, thereby raising production efficiency.

The second reason is that assemblers are relocated to a new team and receive job training beforehand, so they can perform multiple tasks whenever exogenous shocks occur in the future. Alternatively, to cope with future shocks, a foreman ex ante provides his own assemblers with job training to perform multiple tasks through rotation within their own team. The third reason is that the proposed Kaizen drafts encourage the reorganization of operational procedures through rotation within a team and the relocation of assemblers across teams, which leads to increases in team productivity and production efficiency. The proposed Kaizen drafts are the ones capturing the supply shock.

According to Monden (1997), ${ }^{5}$ at Toyota Motor Co.'s Tsutsumi factory, not only assemblers but also foremen, supervisors and managers rotate within and across teams. After they became multiskilled, job rotations among all assembly line processes occurred every 2-4 hours. The main purpose of job rotation is to prepare for flexible personnel arrangement in response to exogenous shocks. Monden (1997) suggests some additional merits of job rotation, such as that it prevents assemblers from becoming bored, and that by assigning different tasks, foremen can assign assemblers across operations fairly. Thus veteran assemblers are encouraged to hand down various skills to young assemblers, and assemblers can see the whole picture of the operation process and feel responsible for their own team's goals, while newly assigned assemblers can address problems in a new operation and propose a draft Kaizen for improvements.

\footnotetext{
${ }^{4}$ For example, buyers began to receive tax credits for buying hybrid cars or eco-friendly cars in April 2009 in Japan. Since then the demand for those cars (the Toyota Prius in particular) has been rapidly growing. ${ }^{5}$ See Chapter 11.
} 
Channels 1 and 2 in Figure 1 represent this process.

Monden (1997) also discusses why multiskills are cultivated in Japan, but not in the US. He points out that in US automakers, jobs are excessively classified and that the wage system is determined in each job, which encourages assemblers to specialize in a single operation and does not give assemblers an incentive to learn a range of skills. He finds that because of a lack of OJT, blue-collar assemblers do not have an opportunity to obtain a range of skills.

We should be aware of the cost incurred by undertaking organization adjustments. According to Hildreth and Ohtake (1998), such adjustments incur direct and indirect costs. The direct cost is the transaction cost involved in transfers. There are two types of the indirect cost. The first is the efficiency loss of having an incoming assembler assigned to a different operation process; the other is the loss of the gain that the assembler would have produced in the former operation without his/her transfer.

What the firm can do to minimize possible loss of efficiency is to provide job training to assemblers assigned to new operations, thereby minimizing the initial indirect cost or lowering the efficiency loss. Assemblers relocated to a new team in response to a demand or supply shock are required to perform new tasks, and this encourages those assemblers, even veterans, to receive job training to acquire new skills. Channel 3 in Figure 1 represents this process. In a similar manner, the need for job training arises when an assembler rotates to work on new operations within their own team.

Assemblers provided with job training acquire new skills and should then assess their improvements in productivity. Channel 4 in Figure 1 represents this process. However, even though relocated assemblers provided with job training acquire new skills, because they no longer employ the skills used in the previous team, they may subjectively assess a low productivity gain.

\section{Characterization of the Survey}

We conducted unique surveys of the manufacturing establishments of two different Japanese automobile makers, referred to as Firm A and Firm B to preserve anonymity. The two firms are typical of other automobile makers listed on the First Section of the Tokyo Stock Exchange. The two firms have establishments in Japan and abroad. Each establishment is an independent production unit, producing several different products under the "just-in-time" production system. We completed three waves of the survey for both Firm A and B, so that we have two sets of panels for assemblers and foremen. The distinguishing feature of the surveys is that they cover both assemblers who worked in the assembly line and their foremen, and that both assemblers and foremen subjectively assessed the extent of productivity improvements at the individual level. ${ }^{6}$ This allows us to estimate directly the impact of various types of job training on productivity improvements at the individual level.

We conducted the first wave of the survey of manufacturing establishments for Firm A in September 2006, with the second and third waves carried out in May 2007 and May 2008, respectively. We collected valid responses from 22 foremen and 100

\footnotetext{
${ }^{6}$ The wage level is used as an alternative variable indicating the extent of individual productivity to identify the effect of training on individual productivity (Kawaguchi 2006, Yoshida 2004).
} 
assemblers in the first wave, 23 foremen and 95 assemblers in the second wave, and 17 foremen and 101 assemblers in the final wave. During this time, the entire auto industry was operating at peak capacity, with Firm A especially in constant need of temporary workers. The firm was chronically short of labor, hiring so many temporary workers that regular full-time workers needed to devote much of their time to teaching these irregular workers, and so lacked any spare time to train themselves. It therefore appears conceivable that the sample period is somewhat unusual in terms of the heavy workloads and the large share of untrained irregular workers. It should also be of some relevance that the sample establishment in the Firm A survey has plans in the near future to undergo a very fundamental and thorough redesign and retooling of its production line. This may also have had some impact on work allocation, as well as the assignments of regular assemblers and foremen. The survey targeted only full-time employees.

In a similar manner, we conducted consecutive yearly surveys of the manufacturing establishment of Firm B in October 2007, October 2008, and October 2009. The first wave collected valid responses from 27 foremen and 140 assemblers belonging to one of the assembly teams under the supervision of foremen in the manufacturing establishment. The second wave collected information from 26 foremen and 139 assemblers working in the same establishment. For the third and the last, we collected data from 24 foremen and 127 assemblers.

The assembler's questionnaire consisted of 20 questions classified into four categories. $^{7}$ These are: (1) the extent of individual-level training intensity (OJT, OffJT, and self-development); (2) the extent of productivity improvements, the acquisition of skills, and the number of fully fledged operational processes that one can perform; (3) the number of proposed Kaizen drafts for job efficiency improvement; and (4) evaluation of one's own foreman, workplace environment, and practices. Meanwhile, the questionnaire for foremen consisted of nine questions on the workplace environment and practices in their assembly team, the number of quality control (QC) meetings, and the productivity improvements in their own team.

It is technically difficult to measure productivity improvement per assembler, so we asked for its subjective measurement over the past year. ${ }^{8}$ The survey asked the sample assemblers the following question: "Assuming that your current work proficiency is 100 and that your productivity immediately after you joined the firm and were assigned to a workplace was zero, what do you think your proficiency level was six months and one year ago?" In response, assemblers were required to choose from the following five categories: (1) 100-95, (2) 95-90, (3) 90-85, (4) 85-80, and (5) less than 80. ${ }^{9}$ We used this as a proxy measure of the individual productivity improvement. ${ }^{10}$

\footnotetext{
${ }^{7}$ The questionnaires for both an assembler and a foreman are atahced in Appendix.

${ }^{8}$ Krueger and Rouse (1998) also use subjective data to measure the extent and intensity of individual productivity and then estimate the effects of corporate training consisting of basic skills development, including reading, writing, and mathematics.

${ }^{9}$ This survey rules out the possibility that an assembler perceives that productivity has deteriorated during the past year. We justify this on the basis that human capital accumulates year by year through job training and barely depreciates in the short run.

${ }^{10}$ The sampled foremen were also questioned about the improvement in productivity in their own team in a subjective way as follows: "If the productivity of your workplace 12 months ago was 100, what do you think the productivity levels were 6 months ago and today?” In response, the foremen were to fill in any number, implying productivity improvements if the number exceeded 100, otherwise a productivity
} 
To complement the subjective measure of individual productivity, we alternatively used the extent of how many operational tasks an assembler had newly acquired over the past year. We consider assemblers who can acquire additional operational tasks as those accomplishing productivity improvements at the individual level. ${ }^{11}$ Because it is not difficult for assemblers to count the number of operational tasks they can perform satisfactorily, we regard this variable as an objective measure with little measurement error. Unfortunately, we could obtain the data on operational tasks only from the third wave of the survey from Firm B. The factory director of Firm B told us that assemblers measured their own productivity improvement based on the increase in the number of operational tasks approved by their own foreman. A table of accomplished operational tasks was prepared for all assemblers and posted on the bulletin board, so everyone understood who had acquired new tasks and how many. We presume from the factory director's evidence that the subjective assessment of productivity improvement is assessed from this objective measure of the operational tasks.

We collected data on the extent of various types of job training, including OJT, OffJT and self-development. Due to limited space, however, we restrict ourselves to the extent and intensity of OJT and its effect on improvements in productivity at the individual level. Measuring the intensity of individual-level OJT is subjective and selfexplanatory in this study, while tenure or years of service has hitherto been a proxy indicating the extent of training, on the assumption that assemblers in the workplace are provided with training. ${ }^{12}$ We asked assemblers several questions concerning OJT intensity. ${ }^{13}$ The OJT dummy took a value of one if an assembler responded with nonzero hours for OJT in the previous month or if the assembler responded that there was less OJT than usual, even if the category including zero OJT hours in the previous month was chosen; otherwise zero. We capture the provision of OJT in the broad sense that assemblers spent time in OJT over the past year, even though they did not receive any in the previous month. We calculate the hours spent in OJT by multiplying the hours of OJT in the past month by 12 . We then divide by $2.5,1.5,1,0.5$, or 0.33 if the assembler responded that the hours of OJT in the previous month were more than double, one and a half times, the same amount, about half, or less than half the average, respectively.

However, we need to remind ourselves that these methods cannot accurately measure the extent and intensity of OJT. Because it is difficult for assemblers to identify correctly those job activities considered to be OJT, it is less likely that assemblers are able to measure the frequency and length of OJT accurately, and this leads to measurement error. We also gathered data on demographic and individual characteristics, including age, tenure, education, and duty position. We merge the surveys for foremen and assemblers to estimate the impact of workplace environment and practices on

decline. Because we focus on the impact on an individual employee's productivity, we preclude the analysis of team productivity in this research.

${ }^{11}$ Note that an operational task is different from an operational process in that one operational process comprises multiple operational tasks.

${ }^{12}$ In a similar manner, Kurosawa (2001) collected explicit data on the extent of intensity of training from 44 establishments in Kitakyushu City, Fukuoka between 1993 and 1994.

${ }^{13}$ We asked: how many hours of OJT did you receive in the last month; who provided the OJT (either colleagues or foremen) and how much; and whether they participated in OJT voluntarily or under instructions from their own foreman. 
individual productivity. ${ }^{14}$

\section{Data Analysis}

a. Organization Adjustments (Channels 1 and 2)

We begin with Channels 1 and 2 as depicted in Figure 1. Figure 2 shows the relationship between the number of assemblers within a team and the assembly line speed, as evaluated by the sampled foremen. Assembly line speed is considered as one of the proxies capturing the extent of the demand shock. This analysis also includes data from both Firm A and B. As shown, the number of assemblers increases in a team when the speed of the assembly line also increases, while the number of assemblers decreases in a team with a low assembly line speed. Assemblers were then relocated from the slack team to the busy team to meet the increasing product demands. This implies that assemblers are located across teams efficiently and flexibly in response to frequently arriving shocks. In a similar manner, Figure 3 shows the relationship between the number of assemblers within a team and the workload of the team as evaluated by the sampled foremen. The workload is one indication of the extent of the demand shock. As shown, the number of assemblers increases in a team where the workload increases, but is cut in a team where the workload decreases. This strengthens the view that assemblers are transferred from slack teams into busy teams to cope with frequent demand changes.

We now explore exactly who is relocated across teams through organization adjustments in response to these demand and supply shocks, using the data of individual assemblers. We predict that assemblers relocated to a different team are more likely to receive job training because they must now perform different tasks. Figures 4-6 show differences in the average age, tenure within the firm, and skill level accredited by their own company for assemblers relocated to different teams and those who are not. According to Figure 4, the average age is higher for relocated assemblers, particularly in 2007 and 2009. One possible interpretation is that older and veteran assemblers who can adjust to the environmental changes more quickly than younger assemblers are relocated to completely different teams where their current skills are useless and therefore, they still need to acquire new skills to engage in different operations. We obtain almost similar results in Figures 5 and 6.

\section{b. Training (Channel 3)}

We now focus attention on whether the arrival of demand and supply shocks encourages assemblers to receive job training, as depicted in Channel 3 in Figure 1. Figure 7 indicates the extent of job training and its average hours using the rate of change in operational processes within the same team on the horizontal axis; this generally shows that the higher the rate of change in operational processes within the team, whether an increase or a decrease, the more likely assemblers are to receive OJT. This implies that assemblers were required to receive OJT, to respond to the reorganization of their own assembly line caused by the arrival of a demand shock. However, the null hypothesis that the OJT incidence does not vary by the rate of change

\footnotetext{
${ }^{14}$ To be comparable, Kurosawa, Ohtake and Ariga (2005) originally collected two-period panel data from 830 randomly selected manufacturing establishments, including information on workplace practices, human resource management and training.
} 
in operational processes is not significantly rejected. We obtain a roughly similar result when we consider the association between the average hours of job training and the change in operational processes; that is, the higher the rate of change in operational processes within the team, the longer assemblers spend in OJT. However, again, the null hypothesis that the average OJT hours do not differ by the rate of change in operational processes is not significantly rejected. The extent and intensity of OJT and the rate of change in operational processes are apparently but not significantly associated.

We explored here whether and when assemblers relocated to a different team receive job training. Figure 8 displays the extent and intensity of OJT, depending on the timing of the relocation across teams. We find that assemblers relocated more recently to a different team are more likely to receive OJT. This is perhaps because newcomers needed to receive job training to accommodate new tasks in the assembly line. However, the difference in the timing of job training less than six months and within one year is minimal. A similar phenomenon is evident in the relationship between average training hours and the timing of relocation. Here, assemblers relocated within six months spend more hours on OJT than those relocated within one year.

\section{c. Productivity Improvements (Channel 4)}

This subsection provides descriptive statistics of the improvement in productivity as measured by subjective assessment. Recall that the survey requested the sampled assemblers to respond on their work proficiency of a year ago from the following five categories: (1) 100-95, (2) 95-90, (3) 90-85, (4) 85-80, and (5) less than 80, assuming that the current work proficiency is 100 . We then calculate the class values of work proficiency according to a lognormal distribution function. Table 1 provides these class values. We consider the increase in work proficiency as a proxy for productivity improvements.

We now explore the relationship between the improvement in individual productivity and job training. Figure 9 displays the proportion of assemblers receiving OJT and its average hours by category of productivity improvement. The horizontal axis represents the categories of work proficiency of a year ago, assuming that the current work proficiency is 100 , and therefore implies that productivity improves as we move further away from the origin on the horizontal axis. We combine data from both firms in Figure 9. As shown, assemblers who stayed in the lower category of work proficiency a year ago are more likely to receive OJT. The null hypothesis that the OJT incidence does not vary by the category of work proficiency is rejected with the level of significance. However, over $80 \%$ of assemblers receive OJT, regardless of the extent of work proficiency. This is consistent with the practice of continuous training for any productivity level. According to the relationship between productivity improvements and hours spent in OJT, assemblers spend on average at least 100 hours per year in OJT. Assemblers who perceive lower improvements in productivity (a 90-95 work proficiency level a year ago) spend the longest hours in OJT. This could also be a form of reverse causality in the sense that those accomplishing low improvements in productivity put more effort into job training.

We have so far not considered the direction of causality between training and productivity; that is, either high-productivity assemblers are less likely to receive job training or those who receive job training succeed in improving their productivity. To control for this reverse causality, Figure 10 shows the extent of subjectively assessed 
productivity improvement by participation in OJT over the past year, using data from both firms. We compute the class values of current work proficiency, assuming that the work proficiency of a year ago is 100 , and they are displayed in the left vertical axis. The horizontal axis is then a one-year lagged indicator of whether to participate in job training as of a year ago. This should take account of the reverse causality problem. As shown, assemblers who received OJT perceived higher productivity improvements than those who did not. This implies that OJT is effective in raising productivity.

\section{d. Operational Tasks (Channel 4)}

To complement the subjective assessment of productivity improvement at an individual level, we alternatively employ how many more operational tasks an assembler newly acquired over the past year. This is because we consider additional operational tasks as productivity improvements at the individual level. This variable can also be objective with little measurement error because both assemblers and their foreman can correctly number the operational tasks they can sufficiently perform. Unfortunately, the data on operational tasks are available only from the third wave of the survey from Firm B. Whether an operational task is accomplished or not is determined by one's own foreman. A table of accomplished operational tasks is posted on the bulletin board, so everyone knows who acquires how many operational tasks.

Table 2 provides the correlations between the subjectively assessed productivity improvement and an increase in the number of operational tasks using the data from the third wave of Firm B. As shown, assemblers acquiring more (fewer) operational tasks respond with higher (lower) productivity improvements. This implies that the subjective and objective measures of productivity improvement are strongly correlated. This is consistent with the evidence provided by the factory director of Firm B, who stated in the interview that assemblers measured their own productivity improvement based on the increase in the number of operational tasks posted on the bulletin board when completing the questionnaire. We are concerned about the relationship between productivity improvements, as measured by an increase in the number of operational tasks, and the extent and intensity of OJT. According to Figure 11, we obtain a positive relationship between the increase in operational tasks and the proportion of those receiving OJT. Looking at the relationship between the increase in operational tasks and job training hours, assemblers who acquire more operational tasks spend more hours on OJT at a moderate level of increase in operational tasks (about 101-150). The extent and intensity of OJT are positively but weakly correlated with productivity improvements with respect to the measure of operational tasks. ${ }^{15}$

We again take into consideration the direction of causality. Figure 10 shows the productivity improvement as measured by the increase in the number of operational tasks and participation in job training in the previous year. The right vertical axis represents the number of operational tasks that one can perform currently, assuming that its number of a year ago is normalized at 100. The horizontal axis is a one-year lagged indicator of whether to participate in job training as of a year ago to take account of the reverse causality problem. Assemblers who receive OJT experience the accomplishment of more operational tasks than those who do not, although the null hypothesis that there

\footnotetext{
${ }^{15}$ We significantly reject the null hypothesis that the OJT incidence does not differ by an increase in operational tasks, but cannot significantly reject the null hypothesis that the average OJT hours differ by an increase in operational tasks.
} 
is no difference of an increase in the number of operational tasks is not significantly rejected. This partially implies that OJT is effective in improving productivity as measured by the number of operational tasks at the individual level.

\section{Estimations}

We pool the data for each firm for estimation purposes. The appendix section shows a list of variables, their definitions and descriptive statistics. We first attempt to estimate the relationship between the productivity shock and organization adjustments, including rotation within the same team and relocation across teams, using the team-average data. Here, we employ the extent of assembly line speed (speed) and the workload (workload) as variables capturing the demand shocks. Kaizen drafts suggested from inside and outside the same team (kaizen_in and kaizen_out) and change in the way of conducting QC meetings within the same team (d_change_qc) are used as variables capturing supply shocks. These variables are drawn from the responses in the foremen' questionnaire. The dependent variable of rotation is a categorized variable indicating that foremen responded that the opportunities for rotation for their own assemblers within the team increased, remained the same, or decreased (rotation) over the year. We specify the team-average years assigned in the current team as a dependent variable indicating the extent of relocation across teams (exp_gr).

We next use a probit model for estimating the propensity that an individual assembler receives training while a Tobit model yields the equation for hours of training. The dependent variable is the propensity to receive job training in the probit model (ojt) and the censored variable of hours spent in job training in the Tobit model (ojt12). Explanatory variables indicate individual characteristics and workplace environments and practices. The individual characteristics include education (d_hs), tenure within the firm (tenure), tenure within the current team (exp), and skill level (skill). The workplace environments and practice include the number of operational processes in the same team (allp), its change over the year (allpdiff), whether there is an increase in opportunities for rotation for assemblers within the same team (rotation2), a change in the way of conducting QC meetings within the same team (d_change_qc), and the extent of OJT for other assemblers within the same team and for all other teams (ojt_within, ojt12_within, ojt_all, and ojt12_all). ${ }^{16}$ For these characteristics, we collected subjectively assessed data from assemblers and foremen. The primary focus is the effects of rotation and relocation (as measured by tenure within the current team) on the provision of job training. Another hypothesis is that the frequent meetings and opportunities for individual development through QC meetings and Kaizen proposals raise assembler morale, thereby encouraging them to participate in and spend more hours in job training.

It might be true that rotation within the same team should be treated as endogenous because whether or not to rotate is an option determined by the foreman. To control for the potential endogeneity of rotation within the same team, we employ two approaches for the two-stage estimation. The first is a standard probit model with instruments; that is, the first stage consists of an OLS estimation of the choice of rotation to derive the

\footnotetext{
${ }^{16}$ Note that rotation is the categorized variable while rotation2 is the dummy indicating one if an assembler receives OJT and zero otherwise. In addition, note that exp represents tenure within the current team while exp_gr indicates team-average years assigned in the current team.
} 
predicted value, and it is then used as an instrument variable in the probit estimation of OJT incidence and the OLS estimation of OJT duration. As the second approach, we employ the recursive maximum likelihood method. The first stage uses a probit estimation of the choice of rotation, and then the predicted value is included as an instrument variable in the second stage.

Our attention now turns to the estimation of the effect of training on the improvement in productivity at the individual level. The propensity for productivity improvement is determined by vectors of explanatory variables reflecting individual characteristics, the workplace environment and practices, and either a continuous variable for training hours (ojt12) or a dummy variable taking a value of one if assemblers received training (ojt). The dependent variable represents the likelihood of productivity improvement with respect to either subjective or objective measurement $(r r$ and oaskl_gr). Our principal focus is the estimated coefficient of the training variable. Our hypothesis is that productivity improvements are positively associated with the extent and intensity of training.

\section{Results}

\section{a. Relocation across Teams and Rotation within the Same Team}

We begin by estimating the determinants of relocation across teams and rotation within the same team. We hypothesize that organization adjustments, such as relocation and rotation, are caused by exogenous shocks from both the demand and supply sides, which thereby demand that assemblers receive job training to acquire different skills.

Table 3 provides the results of the ordered probit model estimating the determinants of rotation within the same team where the dependent variable is categorized as -1 for a decrease in rotation opportunities, 0 for unchanged and 1 for an increase in rotation opportunities (rotation) over the past year. The assembly line speed (speed) has a positive effect on the extent of rotation within the same team at the $1 \%$ level of significance in columns (1) and (3), while the workload (workload) is statistically insignificant for rotation. It would then appear that to cope with demand shocks, foremen rotate assemblers across different operations. The variables capturing supply shocks are statistically insignificant for rotation in column (2). Foremen rotate their own assemblers across various operations within their own teams, regardless of whether Kaizen drafts are proposed.

Table 4 displays the results of the OLS models used to estimate the determinants of relocation across teams over the past year. Note that F-values are not large enough to pass an $\mathrm{F}$ test. When the average tenure within the current team is employed as the dependent variable (exp_gr), the workload has a negative effect at the 5\% level of significance although the assembly line speed remains insignificant. Here, as a foreman has a greater burden of workload in his own team, he demands the firm to increase the number of assemblers in his own team, and this reduces average tenure within the current team. The variables capturing supply shocks remain statistically insignificant. It thus appears that demand shocks induce organization adjustments, including relocation of assemblers across teams and rotation of assemblers within the same team.

\section{b. Determinants of Job Training}

Tables 5 and 6 display the estimated results of the probit and Tobit models for the 
determinants of OJT incidence and the hours spent in OJT. We pooled data from both firms and estimated each model. When we look closely at the factors that individually and significantly affect the determinants of job training and its duration, there are certain characterizations of the workplace and the team that affect OJT incidence and its duration for both automobile makers.

It is worth noting from column (5) in Table 5 that when the extent of rotation within the same team (rotation2) is treated as exogenous, it has a positive effect on OJT incidence at the 5\% level of significance. This result supports the hypothesis that assemblers are encouraged to receive OJT and acquire new skills to perform different tasks assigned from transfers through rotation. As discussed, because organization adjustments such as rotation within the same team are efficiently and flexibly undertaken in response to demand shocks, assemblers receive OJT after rotation whenever shocks occur or are expected to occur.

Columns (6) and (7) take into account the interrelation between the OJT incidence and the rotation decision, which thus gives unbiased estimates of the effect of rotation within the same team on OJT participation. Columns (6) and (7) display results of a standard probit model with instruments and a recursive maximum likelihood method, respectively. Similar to column (5), rotation within the same team (rotation2) remains positively significant at the $1 \%$ level in column (6) and at the $5 \%$ level in column (7). On the other hand, tenure within the current team (exp) is insignificant in column (6), but negative at the $10 \%$ level of significance in column (7). After controlling for the endogeneity of rotation, the results remain similar to those of column (5), which ensures that treating rotation as exogenous is acceptable.

According to Table 6, tenure within the current team (exp) has a negative effect on the average hours of OJT at the 5\% level in columns (4) and (5), while rotation within a team (rotation2) is statistically insignificant for the OJT duration when rotation within a team is treated as exogenous. This indicates that assemblers are relocated to a different team in which the skills they have obtained are useless and they then spend more time learning new skills through OJT. After controlling for the endogeneity of rotation, the significance remains unchanged in columns (6) and (7), comparable with column (5), although the magnitudes of some coefficients are different.

Looking at Table 6, the number of operational processes in a team (allp) is negative for OJT hours at the $1 \%$ level of significance. This implies that assemblers either cannot afford to spend time on OJT in a busy team in which there are many operational processes or, because they operate only a few simple tasks in one operation process if operational tasks are segmented into many operation processes, they do not need to spend time on OJT. Columns (5)-(7) in both tables indicate that the average OJT incidence and duration of any other assembler across all teams (ojt_all and ojt12_all) are significantly negative for an assembler's own OJT incidence and its duration. This implies that one assembler receives OJT when other assemblers do not. It would then appear that OJT is substitutable between assemblers; that is, one receives OJT while another cannot. In contrast with our prediction, skill level and tenure within the firm are statistically insignificant for both OJT incidence and its duration. ${ }^{17}$

\footnotetext{
${ }^{17}$ According to Kurosawa (2006), assemblers with shorter tenure are more likely to participate in OffJT and self-development programs. However, the impact on the incidence of OJT is not addressed.
} 


\section{c. Does Job Training Improve Productivity?}

This subsection reports the effect of job training on the improvements in subjective and objective productivity. We estimate OLS models where the dependent variable represents the extent of productivity improvement over the past year.

We begin with explaining the estimated results shown in Tables 7 and 8 . The incidence of job training is included in the explanatory variable vector in the former while the duration of job training is included in the latter. Of first and foremost interest among the dependent variables are the dummies indicating the incidence of job training and the continuous variables for hours of job training. As shown in Table 7, the incidence of OJT (ojt) has a positive effect on improvement in productivity at the 1\% level of significance. As one would expect, this supports the hypothesis that OJT contributes to making an individual assembler more productive from a subjective viewpoint. This result is partially comparable with those obtained in Kurosawa (2001) and Ariga, Kurosawa and Ohtake (2006); in the former, the effect on wages does not clearly differ by the form of training, ${ }^{18}$ and in the latter OJT participation has an insignificant effect on establishment-level productivity. ${ }^{19}$ Our concern now is the effects of OJT duration. In contrast with our prediction, OJT duration (ojt12) is statistically insignificant for the improvement in productivity according to Table 8.

Some other factors affect the improvements in productivity. Tenure within the current team (exp) has a significant negative effect on individual productivity improvement at the 1\% level of significance in columns (4)-(6) in both Tables 7 and 8. Tenure within the current team, which proxies the extent of relocation across teams, contributes negatively to the improvement in productivity directly and indirectly through the channel of the demand for job training. The implication of the direct effect is that assemblers realize that productivity increases less proportionally with tenure within the current team, and this is consistent with the general property of diminishing marginal returns. This finding suggests that specialization in certain tasks in the same team discourages an assembler from perceiving an improvement in productivity. The indirect effect is that assemblers who stay long in the current team do not need to receive OJT to learn new skills, which does not raise their productivity. The improvement in productivity assessed from a subjective viewpoint in the previous year ( $r$ __past) has a positive effect on that subjectively assessed in the current year at the 1\% level of significance, as shown in both Tables 7 and 8 . This result implies that assemblers who assess higher improvements in productivity in the past year tend to assess higher improvements this year. A change in the way of conducting QC meetings over the past year (d_change_qc) is statistically insignificant, which is comparable with Ariga, Kurosawa and Ohtake (2006) where participation in suggestion meetings has a significantly positive effect on establishment-level productivity.

Here we examine the effect of job training at an individual level on improvements in productivity from an objective viewpoint using the data on the operational tasks that assemblers can sufficiently perform. Recall that the data are only available from the third wave of the survey from Firm B. Because the sample size is small, the standard error may be large, thereby reducing the significance of the variables. Before estimating the effect of job training on productivity improvement as measured by the increase in

\footnotetext{
${ }^{18}$ The exception is that the effect of formal training on wages was significantly negative for assemblers over 45 years of age.

${ }^{19}$ However, the effect of OffJT participation is significantly positive on establishment-level productivity.
} 
the number of operational tasks, we examine the relationship between the productivity improvements from the subjective and objective viewpoints. According to Table 9, an increase in operational tasks is positively correlated with a subjectively assessed improvement in productivity at the $1 \%$ level of significance. Therefore, the increase in operational tasks can be considered an objective variable representing the improvement in productivity from a subjective viewpoint.

Tables 10 and 11 display the OLS estimates where the dependent variable is continuous, indicating the change in the number of operational tasks that assemblers can sufficiently perform (oaskl_gr). First, we cannot significantly reject the joint hypothesis that the coefficients on all explanatory variables are zero according to the $\mathrm{F}$ test. Our estimations thus do not explain much of the variation. Despite this, we report estimated results. The incidence of OJT (ojt) is statistically insignificant for an increased rate of operational tasks. The incidence of OJT is significantly positive for the subjectively assessed improvement in productivity, as shown in Table 7, but insignificant in the model where the increase in operational tasks is the dependent variable. One possible reason is that, as discussed earlier, the small sample size may increase the standard error of the coefficient and therefore reduce the significance. Because the estimates cover the three waves of the survey from both Firms A and B in Table 7 while the estimates in Table 10 include only the third wave of the survey from Firm B, we cannot directly compare the estimated results. The OJT hours (ojt12) are marginally and significantly positive in column (1) in Table 11, but the significance reduces when including other explanatory variables. Accordingly, these estimations do not explain much of the variation in Tables 10 and 11 because of the small sample size.

Although the subjectively assessed improvement in productivity and the increase in operational tasks are statistically correlated, we have different results for the effect of OJT incidence depending on the measure of productivity improvement used as the dependent variable. One possible interpretation is that the individual and workplace characteristics in the three waves for Firms A and B are different from those from the last wave for Firm B.

\section{Cost Effects of Organization Adjustments}

This section briefly discusses a comparison of labor adjustment costs by internal transfer (organization adjustment) with hiring/firing from the external labor market. Table 12 shows that $32.68 \%$ and $19.86 \%$ of assemblers are on average relocated to a different team over one year in Firms A and B, respectively. We calculate the cost that the firm would have incurred if the same percentages of assemblers had been replaced by hiring or firing from the external labor market and then compare it with the adjustment cost of the internal transfer.

Table 12 shows the cost adjusted through the external labor market, normalizing the training cost for an internal assembler to be one, regardless of whether or not to be relocated. The assembler size is normalized at one for simplicity. We consider cases in which the individual cost for job training is higher for a newly hired assembler than for an incoming internal assembler by $10 \%, 25 \%, 50 \%$ and $100 \%$.

In the case of $10 \%$, Firm A would have increased its total training cost by $3.3 \%$ if $32.68 \%$ of assemblers were obtained from the external labor market. In a similar manner with $25 \%, 50 \%$ and $100 \%$, Firm A has the greater burden of training costs by 
8.2\%, 16.3\% and 32.7\%, respectively. Firm B would also have incurred a larger burden of training costs by hiring assemblers from the external labor market. This exercise implies that when labor adjustment frequently and largely occurs in response to demand shocks, labor adjustment through internal transfer such as relocation is cheaper than labor adjustment by hiring from the external labor market.

\section{Concluding Remarks}

It is difficult to measure the effect of job training on productivity at the individual level, but there is no doubt that it is very important for constructing and evaluating a job training strategy from the viewpoint of human resource development. We collected unique data on job training and productivity improvements from the establishments of two Japanese automobile makers and evaluated the subjective impact of OJT on individual productivity improvements. We investigated (1) whether OJT is continuously provided to any assembler, even when each task is easy to learn; (2) the determinants of the extent and intensity of firm-level training such as OJT; and (3) the impact of training and workplace environments and practices on subjective and objective individual productivity improvements.

Our main findings are as follows. (1) OJT is provided to assemblers because they are assigned different operations in which the skills they have thus far obtained become useless through organization adjustment, including both rotation within the same team and relocation to a different team. (2) Organization adjustments are undertaken in response to productivity shocks. (3) Assemblers who receive OJT perceive their gains in productivity from a subjective viewpoint. Another finding is that older and veteran assemblers are more likely to be relocated to a different team because they adapt to change more quickly than do the young, implying that even older and veteran assemblers need to receive job training to perform different tasks following relocation.

Unfortunately, endogeneity of the choice of OJT complicates our estimation strategy. For instance, when there is a negative productivity shock, firms may opt to increase their investment in OJT as the opportunity cost of these activities has declined. If true, the impact of training hours tends to be underestimated. To correct for this endogeneity problem, we attempted to estimate a model with a set of instrumental variables, but none of the variables was significant. As a result, the estimated model itself lost significance. It is also problematic that the period within which we are measuring the impact of training activities on productivity is too short, so we cannot capture a longterm effect of OJT on productivity improvements. Those are our future research directions.

\section{References}

Ariga, Ken, and Giorgio Brunello. 2006. "Are Education and Training always Complements? Evidence from Thailand,” Industrial and Labor Relations Review, Vol. 59, No. 4, pp. 613-629.

Hildreth, Andrew K.G., and Fumio Ohtake. 1998. "Labor Demand and the Structure of Adjustment Costs in Japan," Journal of the Japanese and International Economics, Vol. 12, No. 2, pp.131-50. 
Kawaguchi, Daiji. 2006. "The Incidence and Effect of Job Training among Japanese Women,” Journal of Economy and Society, Vol. 45, No. 3, pp. 469-477.

Koike, Kazuo. 1994. "Learning and Incentive Systems in Japanese Industry," In Masahiko Aoki and Ronald Dore, ed., The Japanese Firm, pp. 41-65, Oxford: Clarendon Press.

Koike, Kazuo. 2002. "Intellectual Skills and Competitive Strength: Is a Radical Change Necessary?” Journal of Education and Work, Vol. 15, No. 4, pp. 391-408.

Krueger, Alan and Cecilia Rouse. 1998. "The Effect of Workplace Education on Earnings, Turnover, and Job Performance,” Journal of Labor Economics, Vol. 16, No. 1, pp. 61-94.

Kurosawa, Masako. 2001. "The Extent and Impact of Enterprise Training: The Case of Kitakyushu City,” Japanese Economic Review, Vol. 52, No. 2, pp. 224-242.

Kurosawa, Masako. 2006. "The Determinants of Participation in OJT and Off-JT," Japan Institute for Labour Policy and Training Material Series, No. 13, pp. 3655.

Kurosawa, Masako, Fumio Ohtake, and Ken Ariga. 2005. "Productivity, Training, and Human Resource Management Practices-Disentangling Complex Interactions using a Survey of Japanese Manufacturing Firms,” Discussion Paper No. 062, Kyoto Institute of Economic Research, Kyoto University.

Leuven, Edwin, and Hessel Oosterbeek. 2005. “An Alternative Approach to Estimating the Wage Returns to Private-Sector Training,” Discussion Paper No. 061, Kyoto Institute of Economic Research, Kyoto University.

Monden, Yasuhiro. 1997. Toyota Production System: An Integrated Approach to Just-InTime, Third Edition, Norcross, Georgia: Engineering \& Management Press.

Yoshida, Keiko. 2004. “An Empirical Analysis of the Impact on Wages of Workers' Self-Development,” Japanese Journal of Labour Studies, No. 532, pp. 40-53 (in Japanese). 
Table 1: Distribution of improvement of productivity with a subjective viewpoint

\begin{tabular}{rllll}
\hline response & & Total & Firm A & Firm B \\
\hline 1 & $95 \sim 100$ & $149(21.88)$ & $40(13.61)$ & $109(28.17)$ \\
2 & $90 \sim 95$ & $159(23.35)$ & $66(22.45)$ & $93(24.03)$ \\
3 & $85 \sim 90$ & $124(18.21)$ & $63(21.43)$ & $61(15.76)$ \\
4 & $80 \sim 85$ & $103(15.12)$ & $53(18.03)$ & $50(12.92)$ \\
5 & $\sim 80$ & $146(21.44)$ & $72(24.49)$ & $74(19.12)$ \\
\hline
\end{tabular}

The categories represent productivity level of one year ago, assuming that the current productivity level is 100 .

Table 2: Correlation between productivity improvement with a subjective viewpoint and an increase in operational tasks that an assembler can perform

\begin{tabular}{cc|rrrrrrr}
\hline & & \multicolumn{7}{c}{ Operational tasks } \\
& & $95 \sim 100$ & $90 \sim 95$ & $85 \sim 90$ & $80 \sim 85$ & $\sim 80$ & Total \\
\hline \multirow{4}{*}{ Productivity } & $95 \sim 100$ & 12 & 0 & 1 & 1 & 3 & 17 \\
improvement & $90 \sim 95$ & 7 & 1 & 1 & 1 & 7 & 17 \\
& $85 \sim 90$ & 6 & 0 & 2 & 0 & 9 & 17 \\
& $80 \sim 85$ & 4 & 0 & 0 & 0 & 8 & 12 \\
& $\sim 80$ & 0 & 1 & 0 & 0 & 23 & 24 \\
& Total & 29 & 2 & 4 & 2 & 50 & 87 \\
\hline
\end{tabular}

The third wave of the survey from Firm B was used.

The horizontal categories indicate the number of operational tasks that one could perform one year ago, assuming that the current number is normalized 100. On the other hand, the vertical categories represent productivity level of one year ago, assuming that the current productivity level is 100 . 
Table 3: Determinants of rotation

\begin{tabular}{|c|c|c|c|c|c|}
\hline & Coefficient & $\mathrm{p}$ value & Coefficient & $\mathrm{p}$ value & Coefficient \\
\hline d_firma & \multicolumn{2}{|c|}{$-0.147[0.519]$} & \multicolumn{2}{|c|}{$-0.247[0.268]$} & $-0.153[0.522]$ \\
\hline Speed & \multicolumn{2}{|c|}{$0.399[0.002]^{* * *}$} & & & $0.394[0.002]^{* * *}$ \\
\hline Workload & \multicolumn{2}{|c|}{$-0.04[0.807]$} & & & $0.017[0.921]$ \\
\hline Injury & \multicolumn{2}{|c|}{0.084 [0.669] } & & & $0.009[0.963]$ \\
\hline kaizen_in & & & \multicolumn{2}{|c|}{$0.258[0.432]$} & 0.313 [0.349] \\
\hline kaizen_out & & & \multicolumn{2}{|c|}{$-0.236[0.324]$} & $-0.175[0.482]$ \\
\hline d_change_qc & & & \multicolumn{2}{|c|}{$0.109[0.674]$} & $0.087[0.751]$ \\
\hline & \multicolumn{2}{|l|}{ obs $=118$} & \multicolumn{2}{|l|}{ obs $=116$} & obs $=114$ \\
\hline & \multicolumn{2}{|c|}{ LR chi2(4) = 11.810} & \multicolumn{2}{|c|}{ LR chi2(4) = 3.230} & LR $\operatorname{chi} 2(7)=13.140$ \\
\hline & \multicolumn{2}{|c|}{ Prob $>$ chi2 $=0.019$} & \multicolumn{2}{|c|}{ Prob $>$ chi2 $=0.520$} & Prob $>$ chi2 $=0.069$ \\
\hline & \multicolumn{2}{|c|}{ Pseudo R2 = 0.054} & \multicolumn{2}{|c|}{ Pseudo R2 = 0.015} & Pseudo R2 = 0.061 \\
\hline
\end{tabular}

$* * * 1 \%$, ** 5\%,* 10\% significance. The dependent variable (rotation) is categorized as -1 for decease, 0 for unchanged and 1 for increase conducted to foremen. The ordered probit estimation method is employed.

Table 4: Determinants of relocation

\begin{tabular}{|c|c|c|c|}
\hline & Coefficient & Coefficient & Coefficient \\
\hline Constant & $6.197[0.000]^{* * *}$ & $5.171[0.000]^{* * *}$ & $5.681[0.000]^{* * *}$ \\
\hline d_firma & $-0.936[0.092]^{*}$ & $-1.261[0.030]^{* *}$ & $-1.139[0.047]^{* *}$ \\
\hline Speed & $-0.102[0.735]$ & & $-0.005[0.987]$ \\
\hline Workload & $-0.829[0.036]^{* *}$ & & $-0.843[0.040]^{* *}$ \\
\hline Injury & $-0.414[0.380]$ & & $-0.551[0.261]$ \\
\hline kaizen_in & & $0.675[0.434]$ & $0.39[0.630]$ \\
\hline kaizen_out & & $0.695[0.264]$ & $0.616[0.299]$ \\
\hline \multirow[t]{6}{*}{ d_change_qc } & & $0.005[0.994]$ & $0.295[0.640]$ \\
\hline & obs $=117$ & obs $=115$ & obs $=113$ \\
\hline & $F(4,112)=1.990$ & $F(4,110)=1.560$ & $F(7,105)=1.750$ \\
\hline & Prob $>F=0.101$ & Prob $>$ F $=0.189$ & Prob $>F=0.106$ \\
\hline & R-squared = 0.066 & R-squared $=0.054$ & R-squared = 0.104 \\
\hline & Adj R-squared $=0.033$ & Adj R-squared $=0.019$ & Adj R-squared $=0.045$ \\
\hline
\end{tabular}

$* * * 1 \%, * * 5 \%, * 10 \%$ significance. The dependent variable is the average tenure within the current team (exp_gr). 
Table 5: Determinants of OJT incidence

(1)

(4)

(5)

(6)

(7)

Coefficient p value Coefficient p value Coefficient p value Coefficient p value Coefficient p value Coefficient p value Coefficient p value

\begin{tabular}{|c|c|c|c|c|c|c|c|}
\hline Constant & $1.966[0.000]^{* * *}$ & $1.278[0.000]^{* * *}$ & $2.147[0.000]^{* * *}$ & $2.381[0.001]^{* * *}$ & $33.22[0.000]^{* * *}$ & $41.514[0.000]^{* * *}$ & $33.566[0.000]^{* * *}$ \\
\hline d_firma & $-0.152[0.371]$ & $-0.022[0.908]$ & $-0.28[0.262]$ & $-0.343[0.206]$ & $-0.559[0.074]^{*}$ & $-0.232[0.373]$ & $-0.579[0.059]^{*}$ \\
\hline allp & $-0.032[0.028]^{* *}$ & & $-0.039[0.097]^{*}$ & $-0.048[0.065]^{*}$ & $-0.046[0.105]$ & $-0.028[0.208]$ & $-0.044[0.107]$ \\
\hline allpdiff & & $-0.009[0.634]$ & $0.013[0.559]$ & $0.02[0.424]$ & $0.017[0.529]$ & $-0.001[0.944]$ & $0.016[0.547]$ \\
\hline tenure & & & & $0.008[0.680]$ & $0.002[0.933]$ & $-0.003[0.815]$ & $0.001[0.959]$ \\
\hline skill & & & & $0.005[0.982]$ & $0.082[0.717]$ & $0.136[0.407]$ & 0.115 [0.599] \\
\hline $\exp$ & & & & $-0.032[0.087]^{*}$ & $-0.033[0.100]$ & $-0.011[0.566]$ & $-0.033[0.094]^{*}$ \\
\hline rotation2 & & & & & $0.401[0.026]^{* *}$ & $1.594[0.000]^{* * *}$ & $0.402[0.024]^{* *}$ \\
\hline d_change_qc & & & & & $-0.379[0.187]$ & $-0.698[0.001]^{* * *}$ & $-0.315[0.263]$ \\
\hline ojt_within & & & & & $0.231[0.705]$ & $-0.589[0.217]$ & $0.187[0.752]$ \\
\hline \multirow[t]{5}{*}{ ojt_all } & & & & & $-34.292[0.000]^{* * *}$ & $-44.401[0.000]^{* * *}$ & $-34.683[0.000]^{* * *}$ \\
\hline & Obs $=566$ & Obs $=317$ & Obs $=317$ & Obs $=291$ & Obs $=285$ & Obs $=287$ & Obs $=305$ \\
\hline & LR chi2(2) $=4.88$ & LR chi2(2) $=0.24$ & LR chi2(3) $=3.03$ & LR chi2(6) = 6.35 & LR chi2 $(10)=24.23$ & \multicolumn{2}{|c|}{ Wald chi2 $(10)=119.84 \mathrm{LR}$ chi2 $(10)=24.21$} \\
\hline & Prob $>$ chi2 $=0.087$ & Prob $>$ chi $2=0.887$ & Prob $>$ chi2 $=0.388$ & Prob $>$ chi2 $=0.385$ & Prob $>$ chi2 $=0.007$ & Prob $>$ chi2 $=0.000$ & Prob $>$ chi $2=0.007$ \\
\hline & Pseudo R2 = 0.013 & Pseudo R2 = 0.001 & Pseudo R2 = 0.014 & Pseudo R2 = 0.032 & Pseudo R2 = 0.121 & & Pseudo R2 = 0.118 \\
\hline
\end{tabular}

$* * * 1 \%, * * 5 \%, * 10 \%$ significance. The dependent variable is the dummy indicating whether or not to receive OJT (OJT). The dummy variable (rotation2) is treated as exogenous in columns (1)-(5) but as endogenous in columns (6) and (7). In column (6), the first stage is an OLS estimation of rotation, while a probit estimation is employed in the first stage in column (7). Both columns employ a probit estimation for the OJT incidence in the second stage. IV for rotation: d_firma, speed, workload, injury, kaizen_in, kaizen_out, d_change_qc 
Table 6: Determinants of OJT hours

(1)

(3)

(4)

(5)

(6)

(7)

Coefficient p value Coefficient p value Coefficient p value Coefficient p value Coefficient p value Coefficient p value Coefficient p value

\begin{tabular}{|c|c|c|c|c|c|c|c|}
\hline Constant & $125.909[0.003]^{* * *}$ & $49.623[0.008]^{* * *}$ & $240.455[0.001] * * *$ & $301.275[0.002]^{* * *}$ & $543.897[0.002]^{* * *}$ & $847.288[0.012]^{* *}$ & $545.950[0.002]^{* * *}$ \\
\hline d_firma & $38.4[0.071]^{*}$ & $55.402[0.027]^{* *}$ & $2.77[0.928]$ & $-11.165[0.729]$ & $13.095[0.713]$ & $10.307[0.801]$ & $13.242[0.711]$ \\
\hline allp & $-3.89[0.042]^{* *}$ & & $-8.967[0.005]^{* * *}$ & $-10.068[0.002]^{* * *}$ & $-8.577[0.008]^{* * *}$ & $-9.323[0.010]^{* * *}$ & $-8.612[0.008]^{* * *}$ \\
\hline allpdiff & & $-0.137[0.952]$ & $4.68[0.101]$ & $5.156[0.072]^{*}$ & $4.235[0.142]$ & $5.838[0.400]$ & $4.224[0.145]$ \\
\hline tenure & & & & $0.009[0.997]$ & $0.259[0.898]$ & $1.119[0.620]$ & $0.251[0.902]$ \\
\hline d_hs & & & & $-26.341[0.608]$ & $-42.858[0.387]$ & $-56.664[0.297]$ & $-42.541[0.393]$ \\
\hline skill & & & & $13.027[0.600]$ & $14.056[0.560]$ & $11.236[0.677]$ & $14.455[0.550]$ \\
\hline exp & & & & $-6.005[0.012]^{* *}$ & $-5.378[0.022]^{* *}$ & $-6.658[0.036]^{* *}$ & $-5.415[0.022]^{* *}$ \\
\hline rotation2 & & & & & $-22.06[0.262]$ & $-138.303[0.210]$ & $-22.238[0.260]$ \\
\hline d_change_qc & & & & & $-51.997[0.129]$ & $-5.875[0.916]$ & $-52.354[0.128]$ \\
\hline ojt12_within & & & & & $0.169[0.166]$ & $0.154[0.257]$ & $0.167[0.173]$ \\
\hline \multirow[t]{5}{*}{ ojt12_all } & & & & & $-2.197[0.074]^{*}$ & $-4.068[0.062]^{*}$ & $-2.212[0.073]^{*}$ \\
\hline & Obs $=565$ & Obs $=317$ & Obs $=317$ & Obs $=311$ & Obs $=305$ & Obs $=287$ & Obs $=305$ \\
\hline & LR chi2(2) $=14.380$ & LR $\operatorname{chi} 2(2)=4.940$ & LR chi2(3) = 13.010 & LR chi2(7) $=21.220$ & LR chi2 $(11)=30.580$ & Wald chi2 $(11)=28.11$ & LR chi2(11) = 30.56 \\
\hline & Prob $>$ chi $2=0.001$ & Prob $>$ chi $2=0.084$ & Prob $>$ chi $2=0.005$ & Prob $>$ chi $2=0.004$ & Prob $>$ chi $2=0.001$ & Prob $>$ chi $2=0.003$ & Prob $>$ chi $2=0.001$ \\
\hline & Pseudo R2 = 0.002 & Pseudo R2 = 0.002 & Pseudo R2 $=0.004$ & Pseudo R2 $=0.006$ & Pseudo R2 $=0.009$ & & Pseudo R2 $=0.010$ \\
\hline
\end{tabular}

$* * * 1 \%, * * 5 \%, * 10 \%$ significance. The dependent variable is the OJT duration (OJT12). The dummy variable (rotation2) is treated as exogenous in

columns (1)-(5) but as endogenous in columns (6) and (7). In column (6), the first stage is an OLS estimation of rotation, while a probit estimation is employed in the first stage in column (7). Both columns employ an OLS estimation for the OJT duration in the second stage.

IV for rotation: d_firma, speed, workload, injury, kaizen_in, kaizen_out, d_change_qc 
Table 7: Determinants of productivity improvement -subjective viewpoint (independent variables: incidence of job training)

\begin{tabular}{|c|c|c|c|c|c|c|c|c|c|c|c|c|}
\hline & \multicolumn{2}{|c|}{ (1) } & \multicolumn{2}{|c|}{ (2) } & \multicolumn{2}{|c|}{ (3) } & \multicolumn{2}{|r|}{ (4) } & \multicolumn{2}{|r|}{ (5) } & \multicolumn{2}{|r|}{ (6) } \\
\hline & Coefficient & $\mathrm{p}$ value & Coefficient & $\mathrm{p}$ value & Coefficient & $\mathrm{p}$ value & $\mathrm{p}$ value & Coefficient & $\mathrm{p}$ value & Coefficient & $\mathrm{p}$ value & p value \\
\hline Constant & 109.871 & {$[0.000]^{* * *}$} & 109.587 & {$[0.000]^{* * *}$} & 70.595 & {$[0.000]^{* * *}$} & 77.807 & {$[0.000]^{* * *}$} & 77.844 & {$[0.000]^{* * *}$} & 341.929 & {$[0.002]^{* * *}$} \\
\hline d_firma & 3.116 & {$[0.000]^{* * *}$} & 2.189 & [0.125] & 1.272 & [0.350] & 0.593 & {$[0.676]$} & 0.622 & [0.663] & 7.873 & {$[0.018]^{* *}$} \\
\hline ojt & 4.255 & {$[0.001]^{* * *}$} & 6.223 & {$[0.001]^{* * *}$} & 5.496 & {$[0.002]^{* * *}$} & 5.697 & {$[0.001]^{* * *}$} & 5.662 & {$[0.002]^{* * *}$} & 5.639 & {$[0.001]^{* * *}$} \\
\hline allp & & & -0.058 & [0.684] & -0.015 & [0.913] & -0.09 & [0.517] & -0.084 & [0.550] & -0.089 & [0.532] \\
\hline allpdiff & & & 0.027 & [0.844] & -0.071 & [0.595] & -0.047 & [0.724] & -0.055 & [0.686] & -0.047 & [0.734] \\
\hline rr_past & & & & & 0.341 & {$[0.000]^{* * *}$} & 0.304 & {$[0.000]^{* * *}$} & 0.304 & {$[0.000]^{* * *}$} & 0.298 & {$[0.000]^{* * *}$} \\
\hline tenure & & & & & & & -0.07 & {$[0.452]$} & -0.071 & {$[0.447]$} & -0.082 & {$[0.378]$} \\
\hline d_hs & & & & & & & 0.353 & {$[0.871]$} & 0.273 & [0.901] & 0.106 & [0.961] \\
\hline skill & & & & & & & 0.398 & {$[0.716]$} & 0.427 & [0.699] & 0.547 & [0.619] \\
\hline exp & & & & & & & -0.3 & {$[0.005]^{* * *}$} & -0.302 & {$[0.004]^{* * *}$} & -0.343 & {$[0.001]^{* * *}$} \\
\hline d_change_qc & & & & & & & & & -0.395 & {$[0.788]$} & -0.325 & [0.825] \\
\hline rr_within & & & & & & & & & & & -0.134 & [0.182] \\
\hline \multirow[t]{6}{*}{ rr_all } & & & & & & & & & & & -2.181 & {$[0.022]^{* *}$} \\
\hline & \multicolumn{2}{|l|}{ Obs $=680$} & \multicolumn{2}{|l|}{ Obs $=311$} & \multicolumn{2}{|l|}{ Obs $=305$} & \multicolumn{2}{|c|}{ Obs $=301$} & \multicolumn{2}{|c|}{ Obs $=301$} & \multicolumn{2}{|c|}{ Obs $=300$} \\
\hline & \multicolumn{2}{|c|}{$F(2,677)=13.54$} & \multicolumn{2}{|c|}{$F(4,306)=4.25$} & \multicolumn{2}{|c|}{$F(5,299)=11.51$} & \multicolumn{2}{|c|}{$\mathrm{F}(9,291)=7.54$} & \multicolumn{2}{|c|}{$F(10,290)=6.77$} & \multicolumn{2}{|c|}{$F(12,287)=6.38$} \\
\hline & \multicolumn{2}{|c|}{ Prob $>F=0.000$} & \multicolumn{2}{|c|}{ Prob $>F=0.002$} & \multicolumn{2}{|c|}{ Prob $>F=0.000$} & \multicolumn{2}{|c|}{ Prob $>F=0.000$} & \multicolumn{2}{|c|}{ Prob $>F=0.000$} & \multicolumn{2}{|c|}{ Prob $>F=0.000$} \\
\hline & \multicolumn{2}{|c|}{ R-squared = 0.039} & \multicolumn{2}{|c|}{ R-squared = 0.053} & \multicolumn{2}{|c|}{ R-squared = 0.161} & \multicolumn{2}{|c|}{ R-squared = 0.189} & \multicolumn{2}{|c|}{ R-squared = 0.189} & \multicolumn{2}{|c|}{ R-squared = 0.211} \\
\hline & \multicolumn{2}{|c|}{ Adj R-squared $=0.036$} & Adj R-squar & $\mathrm{ed}=0.040$ & Adj R-squar & $\mathrm{ed}=0.147$ & Adj R-sq & uared $=0.164$ & Adj R-sq & uared $=0.161$ & Adj R-sq & Iared $=0.178$ \\
\hline
\end{tabular}

$* * * 1 \%, * * 5 \%, * 10 \%$ significance. The dependent variable is rotation. 
Table 8: Determinants of productivity improvement - subjective viewpoint (independent variables: hours of job training)

\begin{tabular}{|c|c|c|c|c|c|c|c|c|c|c|c|c|}
\hline & \multicolumn{2}{|c|}{ (1) } & \multicolumn{2}{|c|}{$(2)$} & \multicolumn{2}{|c|}{ (3) } & \multicolumn{2}{|c|}{ (4) } & \multicolumn{2}{|c|}{ (5) } & \multicolumn{2}{|c|}{ (6) } \\
\hline & Coefficient & $\mathrm{p}$ value & Coefficient & $\mathrm{p}$ value & Coefficient & $\mathrm{p}$ value & Coefficient & $\mathrm{p}$ value & Coefficient & $\mathrm{p}$ value & Coefficient & $\mathrm{p}$ value \\
\hline Constant & 113.702 & {$[0.000] * * *$} & 115.292 & {$[0.000]^{* * *}$} & 75.038 & {$[0.000]^{* * *}$} & 83.022 & {$[0.000]^{* * *}$} & 83.05 & {$[0.000] * * *$} & 337.04 & {$[0.002] * * *$} \\
\hline d_firma & 3.092 & {$[0.000] * * *$} & 1.858 & [0.199] & 0.957 & {$[0.487]$} & 0.234 & {$[0.871]$} & 0.286 & {$[0.843]$} & 7.245 & {$[0.033]^{* *}$} \\
\hline ojt12 & 0.00005 & [0.963] & 0.004 & {$[0.202]$} & 0.003 & [0.415] & 0.001 & [0.641] & 0.001 & {$[0.690]$} & 0.001 & [0.833] \\
\hline allp & & & -0.082 & {$[0.570]$} & -0.041 & {$[0.763]$} & -0.127 & {$[0.370]$} & -0.118 & {$[0.411]$} & -0.129 & {$[0.373]$} \\
\hline allpdiff & & & 0.037 & [0.793] & -0.061 & {$[0.654]$} & -0.031 & [0.818] & -0.044 & {$[0.749]$} & -0.034 & [0.808] \\
\hline rr_past & & & & & 0.348 & {$[0.000] * * *$} & 0.313 & {$[0.000]^{* * *}$} & 0.313 & {$[0.000]^{* * *}$} & 0.309 & {$[0.000] * * *$} \\
\hline tenure & & & & & & & -0.066 & {$[0.485]$} & -0.068 & {$[0.476]$} & -0.08 & {$[0.396]$} \\
\hline d_hs & & & & & & & -0.155 & [0.944] & -0.289 & [0.897] & -0.484 & [0.828] \\
\hline skill & & & & & & & 0.43 & {$[0.700]$} & 0.479 & {$[0.670]$} & 0.594 & {$[0.596]$} \\
\hline exp & & & & & & & -0.321 & {$[0.003] * * *$} & -0.324 & {$[0.003]^{* * *}$} & -0.369 & {$[0.001] * * *$} \\
\hline d_change_qc & & & & & & & & & -0.654 & {$[0.665]$} & -0.635 & {$[0.673]$} \\
\hline rr_within & & & & & & & & & & & -0.148 & {$[0.148]$} \\
\hline \multirow[t]{6}{*}{ rr_all } & & & & & & & & & & & -2.078 & {$[0.033]^{* *}$} \\
\hline & \multicolumn{2}{|l|}{ Obs $=679$} & \multicolumn{2}{|l|}{ Obs $=311$} & \multicolumn{2}{|l|}{ Obs $=305$} & \multicolumn{2}{|l|}{ Obs $=301$} & \multicolumn{2}{|l|}{ Obs $=301$} & \multicolumn{2}{|l|}{ Obs $=300$} \\
\hline & \multicolumn{2}{|c|}{$F(2,676)=7.84$} & \multicolumn{2}{|c|}{$F(4,306)=1.76$} & \multicolumn{2}{|c|}{$F(5,299)=9.36$} & \multicolumn{2}{|c|}{$F(9,291)=6.18$} & \multicolumn{2}{|c|}{$F(10,290)=5.57$} & \multicolumn{2}{|c|}{$F(12,287)=5.34$} \\
\hline & \multicolumn{2}{|c|}{ Prob $>F=0.000$} & \multicolumn{2}{|c|}{ Prob $>F=0.137$} & \multicolumn{2}{|c|}{ Prob $>F=0.000$} & \multicolumn{2}{|c|}{ Prob $>F=0.000$} & \multicolumn{2}{|c|}{ Prob $>F=0.000$} & \multicolumn{2}{|c|}{ Prob $>F=0.000$} \\
\hline & \multicolumn{2}{|c|}{ R-squared = 0.023} & \multicolumn{2}{|c|}{ R-squared = 0.023} & \multicolumn{2}{|c|}{ R-squared = 0.135} & \multicolumn{2}{|c|}{ R-squared = 0.161} & \multicolumn{2}{|c|}{ R-squared = 0.160} & \multicolumn{2}{|c|}{ R-squared = 0.182} \\
\hline & \multicolumn{2}{|c|}{ Adj R-squared $=0.020$} & \multicolumn{2}{|c|}{ Adj R-squared $=0.010$} & Adj R-squar & $\mathrm{ed}=0.121$ & Adj R-squar & $\mathrm{ed}=0.135$ & Adj R-squar & $\mathrm{ed}=0.132$ & Adj R-squar & $\mathrm{d}=0.148$ \\
\hline
\end{tabular}

*** $1 \%$, ** 5\%, * 10\% significance. The dependent variable is rotation. 
Table 9: Subjective and objective productivity

\begin{tabular}{|c|c|c|c|c|}
\hline & Coefficient & $\mathrm{p}$ value & Coefficient & $\mathrm{p}$ value \\
\hline Constant & 109.373 & {$[0.000]^{* * *}$} & 105.683 & {$[0.000]^{* * *}$} \\
\hline oaskl_gr & 0.016 & {$[0.000]^{* * *}$} & 0.016 & {$[0.000]^{* * *}$} \\
\hline tenure & & & -0.295 & {$[0.055]^{*}$} \\
\hline d_hs & & & 7.821 & {$[0.020]^{* *}$} \\
\hline skill & & & 0.903 & [0.610] \\
\hline \multirow[t]{6}{*}{ exp } & & & -0.211 & {$[0.210]$} \\
\hline & \multicolumn{2}{|l|}{ Obs $=95$} & \multicolumn{2}{|l|}{ Obs $=92$} \\
\hline & \multicolumn{2}{|c|}{$F(1,93)=18.830$} & \multicolumn{2}{|c|}{$F(5,86)=6.150$} \\
\hline & \multicolumn{2}{|c|}{ Prob $>F=0.000$} & \multicolumn{2}{|c|}{ Prob $>F=0.000$} \\
\hline & \multicolumn{2}{|c|}{ R-squared = 0.168} & \multicolumn{2}{|c|}{ R-squared = 0.264} \\
\hline & \multicolumn{2}{|c|}{ Adj R-squared $=0.160$} & \multicolumn{2}{|c|}{ Adj R-squared $=0.221$} \\
\hline
\end{tabular}


Table 10: Determinants of a change in the number of operational tasks (independent variables: incidence of job training)

\begin{tabular}{|c|c|c|c|c|c|c|c|c|}
\hline & \multicolumn{2}{|c|}{$(1)$} & \multicolumn{2}{|c|}{ (2) } & \multicolumn{2}{|c|}{ (3) } & \multicolumn{2}{|c|}{ (4) } \\
\hline & Coefficient & $\mathrm{p}$ value & Coefficient & $\mathrm{p}$ value & Coefficient & $\mathrm{p}$ value & Coefficient & $\mathrm{p}$ value \\
\hline Constant & 101.786 & {$[0.265]$} & -56.909 & [0.713] & -155.65 & {$[0.380]$} & -209.694 & {$[0.231]$} \\
\hline ojt & 64.034 & [0.499] & 68.482 & {$[0.483]$} & 73.892 & {$[0.304]$} & 73.186 & {$[0.294]$} \\
\hline tenure & & & 6.935 & [0.117] & -4.342 & {$[0.230]$} & -4.166 & {$[0.235]$} \\
\hline d_hs & & & 104.093 & {$[0.280]$} & 118.773 & {$[0.088]^{*}$} & 103.543 & {$[0.127]$} \\
\hline skill & & & 7.971 & {$[0.878]$} & 75.092 & {$[0.065]^{*}$} & 81.032 & {$[0.042]^{* *}$} \\
\hline exp & & & -7.082 & {$[0.152]$} & -1.097 & {$[0.794]$} & -0.335 & {$[0.935]$} \\
\hline allp & & & & & 3.437 & {$[0.441]$} & 6.432 & {$[0.165]$} \\
\hline allpdiff & & & & & -6.449 & {$[0.130]$} & -6.601 & {$[0.111]$} \\
\hline \multirow[t]{6}{*}{ d_change_qc } & & & & & & & -101.260 & {$[0.059]^{*}$} \\
\hline & \multicolumn{2}{|l|}{ Obs $=95$} & \multicolumn{2}{|l|}{ Obs $=92$} & \multicolumn{2}{|l|}{ Obs $=51$} & \multicolumn{2}{|l|}{ Obs $=51$} \\
\hline & \multicolumn{2}{|c|}{$F(1,93)=0.46$} & \multicolumn{2}{|c|}{$F(5,86)=1.41$} & \multicolumn{2}{|c|}{$F(7,43)=1.13$} & \multicolumn{2}{|c|}{$F(8,42)=1.52$} \\
\hline & \multicolumn{2}{|c|}{ Prob $>F=0.500$} & \multicolumn{2}{|c|}{ Prob $>F=0.230$} & \multicolumn{2}{|c|}{ Prob $>$ F = 0.366} & \multicolumn{2}{|c|}{ Prob $>F=0.179$} \\
\hline & \multicolumn{2}{|c|}{ R-squared = 0.005} & \multicolumn{2}{|c|}{ R-squared $=0.076$} & \multicolumn{2}{|c|}{$\mathrm{R}$-squared $=0.155$} & \multicolumn{2}{|c|}{ R-squared $=0.225$} \\
\hline & \multicolumn{2}{|c|}{ Adj R-squared $=-0.006$} & \multicolumn{2}{|c|}{ Adj R-squared $=0.022$} & \multicolumn{2}{|c|}{ Adj R-squared $=0.017$} & \multicolumn{2}{|c|}{ Adj R-squared $=0.077$} \\
\hline
\end{tabular}

$* * * 1 \%, * * 5 \%, * 10 \%$ significance. The dependent variable is an increase in the number of operational tasks (productivity improvement with an objective viewpoint). 
Table 11: Determinants of a change in the number of operational tasks (independent variables: hours of job training)

\begin{tabular}{|c|c|c|c|c|c|c|c|c|}
\hline & \multicolumn{2}{|c|}{ (1) } & \multicolumn{2}{|c|}{$(2)$} & \multicolumn{2}{|c|}{ (3) } & \multicolumn{2}{|c|}{ (4) } \\
\hline & Coefficient & $\mathrm{p}$ value & Coefficient & $\mathrm{p}$ value & Coefficient & $\mathrm{p}$ value & Coefficient & $\mathrm{p}$ value \\
\hline Constant & 138.568 & {$[0.000]^{* * *}$} & -5.450 & [0.961] & -30.202 & [0.854] & -82.356 & [0.611] \\
\hline ojt12 & 0.232 & {$[0.096]^{*}$} & 0.228 & {$[0.107]$} & -0.034 & {$[0.787]$} & -0.039 & {$[0.746]$} \\
\hline tenure & & & 6.525 & {$[0.135]$} & -4.850 & {$[0.186]$} & -4.684 & [0.188] \\
\hline d_hs & & & 115.825 & {$[0.226]$} & 109.553 & {$[0.132]$} & 93.427 & [0.187] \\
\hline skill & & & -0.090 & [0.999] & 71.066 & {$[0.083]^{*}$} & 77.039 & {$[0.054]^{*}$} \\
\hline $\exp$ & & & -7.790 & {$[0.107]$} & -2.326 & {$[0.577]$} & -1.573 & {$[0.698]$} \\
\hline allp & & & & & 2.164 & {$[0.650]$} & 5.111 & [0.296] \\
\hline allpdiff & & & & & -5.599 & {$[0.204]$} & -5.708 & [0.182] \\
\hline \multirow[t]{6}{*}{ d_change_qc } & & & & & & & -101.956 & {$[0.060]^{*}$} \\
\hline & \multicolumn{2}{|l|}{ Obs $=95$} & \multicolumn{2}{|l|}{ Obs $=92$} & \multicolumn{2}{|l|}{ Obs $=51$} & \multicolumn{2}{|l|}{ Obs $=51$} \\
\hline & \multicolumn{2}{|c|}{$F(1,93)=2.83$} & \multicolumn{2}{|c|}{$F(5,86)=1.87$} & \multicolumn{2}{|c|}{$F(7,43)=0.96$} & \multicolumn{2}{|c|}{$\mathrm{F}(8,42)=1.36$} \\
\hline & \multicolumn{2}{|c|}{ Prob $>F=0.096$} & \multicolumn{2}{|c|}{ Prob $>F=0.108$} & \multicolumn{2}{|c|}{ Prob $>F=0.473$} & \multicolumn{2}{|c|}{ Prob $>F=0.242$} \\
\hline & \multicolumn{2}{|c|}{ R-squared = 0.030} & \multicolumn{2}{|c|}{ R-squared $=0.098$} & \multicolumn{2}{|c|}{ R-squared $=0.135$} & \multicolumn{2}{|c|}{ R-squared $=0.206$} \\
\hline & \multicolumn{2}{|c|}{ Adj R-squared $=0.020$} & \multicolumn{2}{|c|}{ Adj R-squared $=0.046$} & \multicolumn{2}{|c|}{ Adj R-squared $=-0.006$} & \multicolumn{2}{|c|}{ Adj R-squared $=0.055$} \\
\hline
\end{tabular}

$* * * 1 \%, * * 5 \%, * 10 \%$ significance. The dependent variable is an increase in the number of operational tasks (productivity improvement with an objective viewpoint). 
Table 12: Comparison of labor adjustment costs from internal transfers and external labor markets

\begin{tabular}{|c|c|c|c|c|c|c|}
\hline & \multicolumn{2}{|l|}{ Firm A } & \multicolumn{2}{|l|}{ FirmB } & \multicolumn{2}{|l|}{ Total } \\
\hline relocated & \multicolumn{2}{|l|}{$32.68 \%$} & \multicolumn{2}{|l|}{$19.86 \%$} & \multicolumn{2}{|l|}{$25.17 \%$} \\
\hline non-relocated & \multicolumn{2}{|l|}{$67.32 \%$} & \multicolumn{2}{|l|}{$80.14 \%$} & \multicolumn{2}{|l|}{$74.83 \%$} \\
\hline & internal adjustment & external adjustment & internal adjustment & external adjustment & internal adjustment & external adjustment \\
\hline $10 \%$ & 1 & 1.033 & 1 & 1.020 & 1 & 1.025 \\
\hline $25 \%$ & 1 & 1.082 & 1 & 1.050 & 1 & 1.063 \\
\hline $50 \%$ & 1 & 1.163 & 1 & 1.099 & 1 & 1.126 \\
\hline $100 \%$ & 1 & 1.327 & 1 & 1.199 & 1 & 1.252 \\
\hline
\end{tabular}

The size of assemblers is normalized one. The cost of training is assumed to be one for an internal assembler, regardless of whether she/he is relocated from a different team or remains in the current team. Therefore, the total cost of training is normalized to be one for internal labor adjustments. 
Figure 1: Chart of demand of job training and its impact on productivity

\begin{tabular}{|c|c|c|c|c|c|c|c|c|}
\hline $\begin{array}{l}\text { demand and } \\
\text { supply shocks } \\
\text { (ex ante \& ex post) }\end{array}$ & $\stackrel{1}{\longrightarrow}$ & $\begin{array}{l}\text { (1) workload } \\
\text { (2) assembly line speed } \\
\text { (3) Kaizen drafts }\end{array}$ & $\stackrel{(2)}{\longrightarrow}$ & $\begin{array}{l}\text { Organizational changes } \\
\text { (1) rotation } \\
\text { within a team }\end{array}$ & (3) & $\begin{array}{l}\text { Job training } \\
\text { (1) OJT } \\
\text { (2) OffJT }\end{array}$ & (4) & $\begin{array}{l}\text { Productivity } \\
\text { improves }\end{array}$ \\
\hline & & (4) QC meeting & & $\begin{array}{l}\text { (2) relocation } \\
\text { across teams }\end{array}$ & & (3) Self-development & & \\
\hline
\end{tabular}

Figure 2: Change in the number of assemblers within a team by the assembly line speed

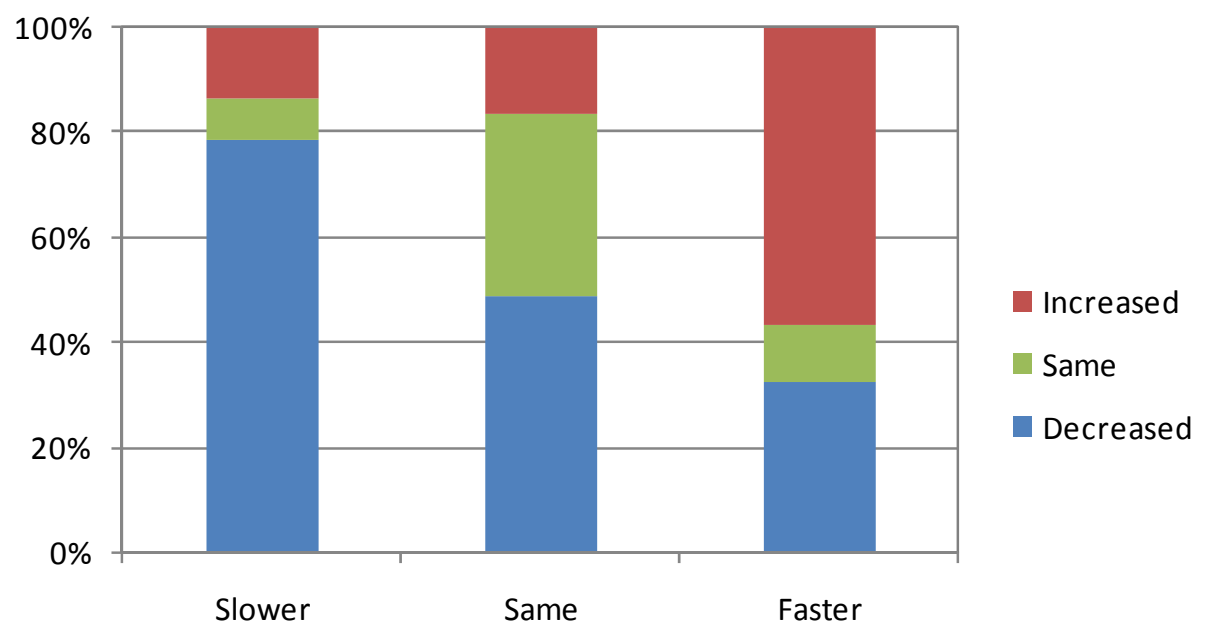

Changes in the line speed (compared to 12 months ago)

Figure 3: Change in the number of assemblers by the burden of workload within a team

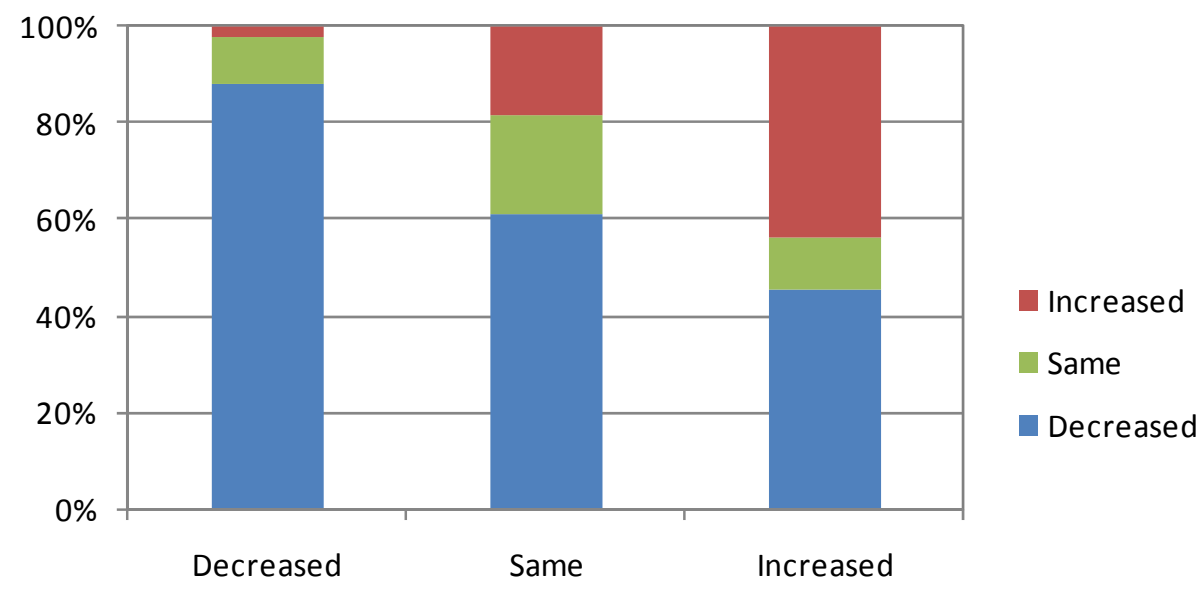

Changes in the workload in the entire workplace (compared to 12 months ago) 
Figure 4: Average age of assemblers relocated to a different team over the past 12 months

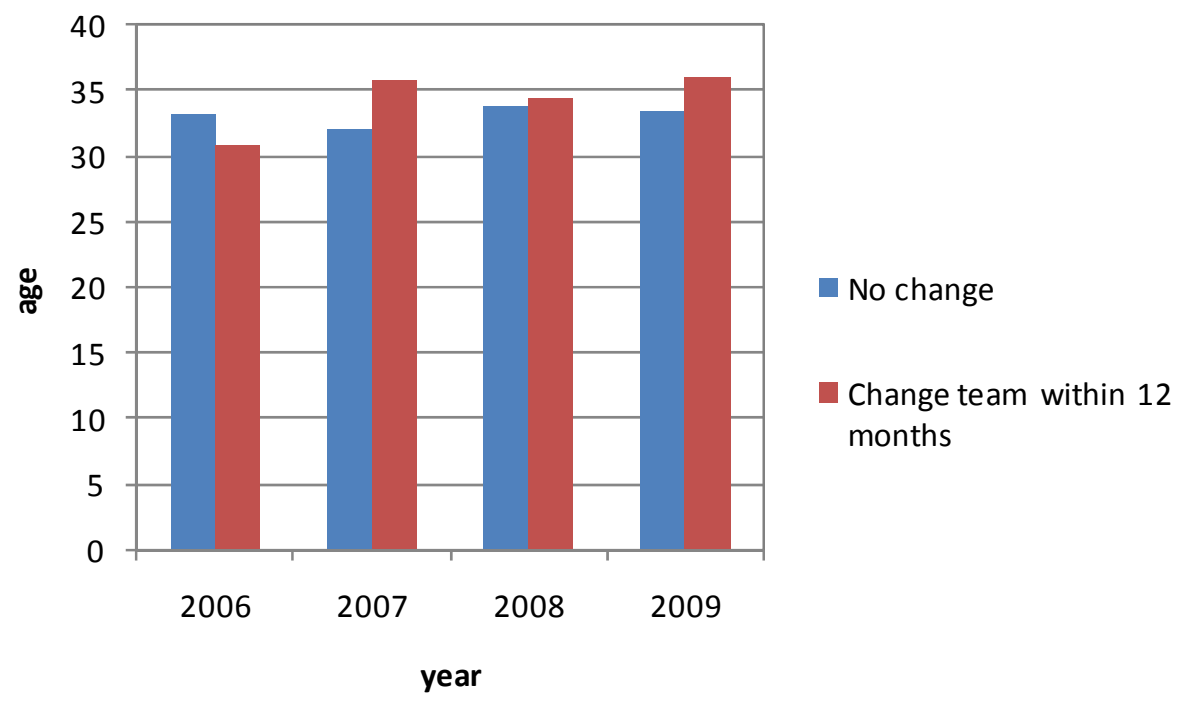

The 2007 and 2008 data are from both Firm A and B. However, the 2006 data are only from Firm A while the 2009 data are only from Firm B. Test for difference $=0$ : 2006: $\mathrm{t}(100)=1.347, \mathrm{p}=0.181$, 2007: $\mathrm{t}(233)=-3.125, \mathrm{p}=0.00,2008: \mathrm{t}(235)=-0.626, \mathrm{p}=0.532,2009: \mathrm{t}(124)=-2.155, \mathrm{p}=0.033$

Figure 5: Average tenure within the firm of assemblers relocated to a different team over the past 12 months

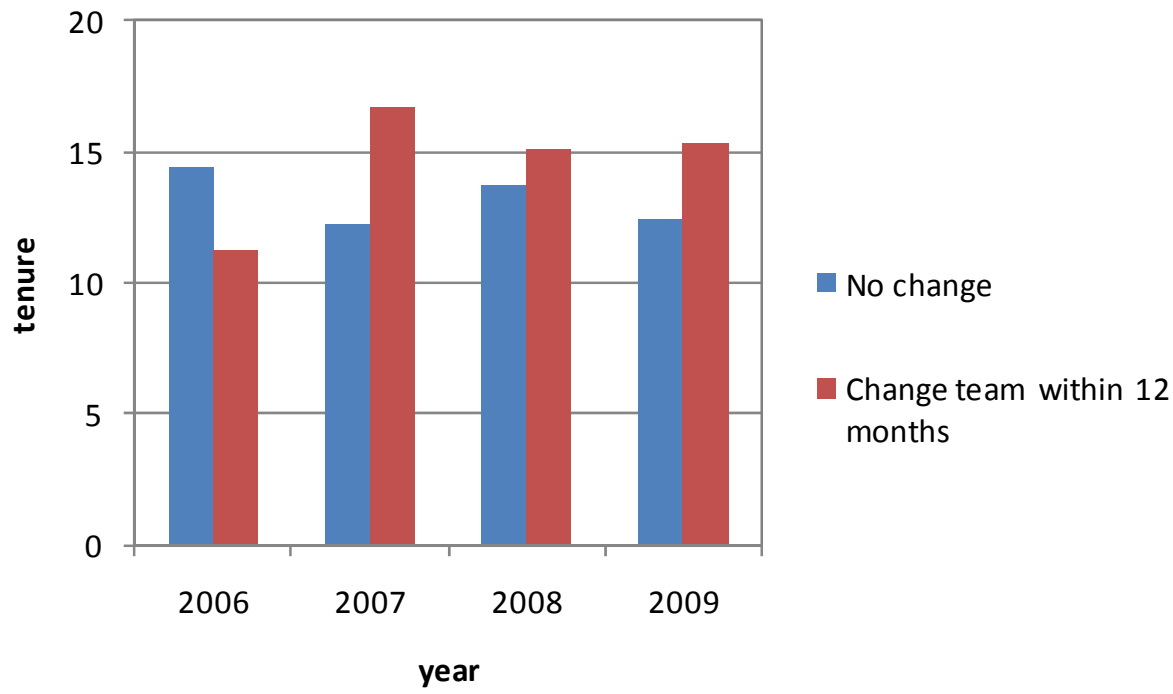

The 2007 and 2008 data are from both Firm A and B. However, the 2006 data are only from Firm A while the 2009 data are only from Firm B. Test for difference $=0$ : 2006: $t(100)=1.831, p=0.070$, 2007: $\mathrm{t}(233)=-3.346, \mathrm{p}=0.001,2008: \mathrm{t}(235)=-1.342, \mathrm{p}=0.181,2009: \mathrm{t}(124)=-2.249, \mathrm{p}=0.026$ 
Figure 6: Average skill level of assemblers relocated to a different team over the past 12 months

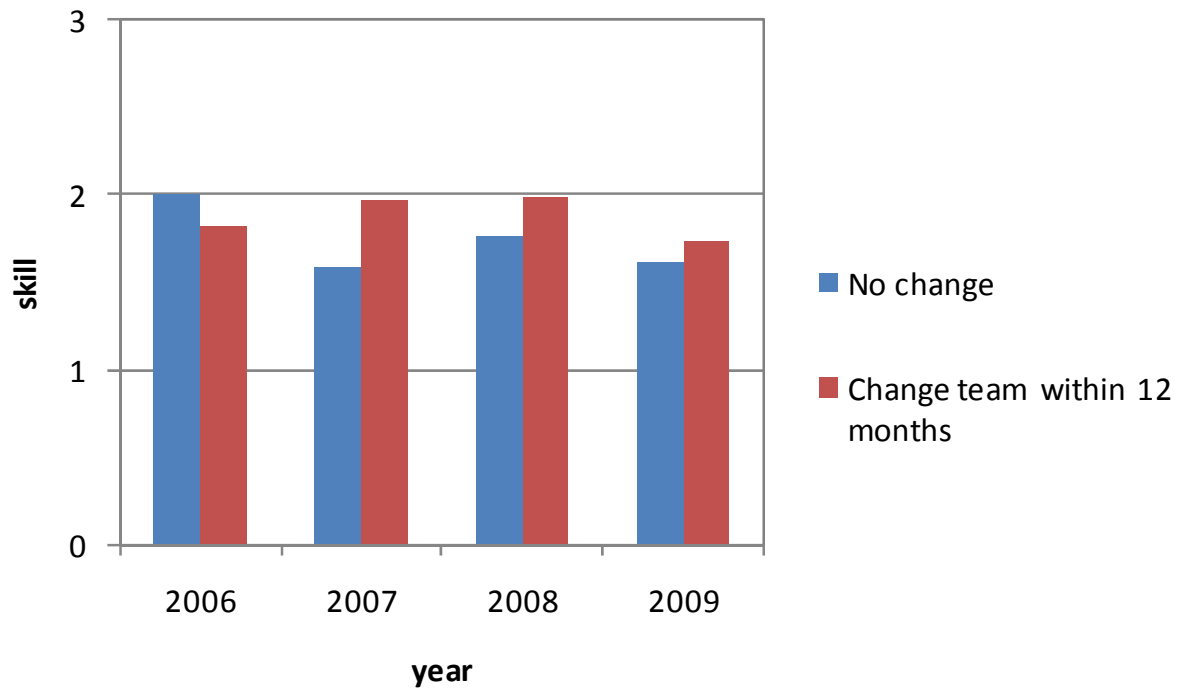

The 2007 and 2008 data are from both Firm A and B. However, the 2006 data are only from Firm A while the 2009 data are only from Firm B., Test for difference $=0$ : 2006: $t(99)=1.182, p=0.240$, 2007: $\mathrm{t}(232)=-2.974, \mathrm{p}=0.003,2008: \mathrm{t}(232)=-2.531, \mathrm{p}=0.012,2009: \mathrm{t}(120)=-1.099, \mathrm{p}=0.274$

Figure 7: Incidence and average hours of job training by a change in the number of operation processes within a team

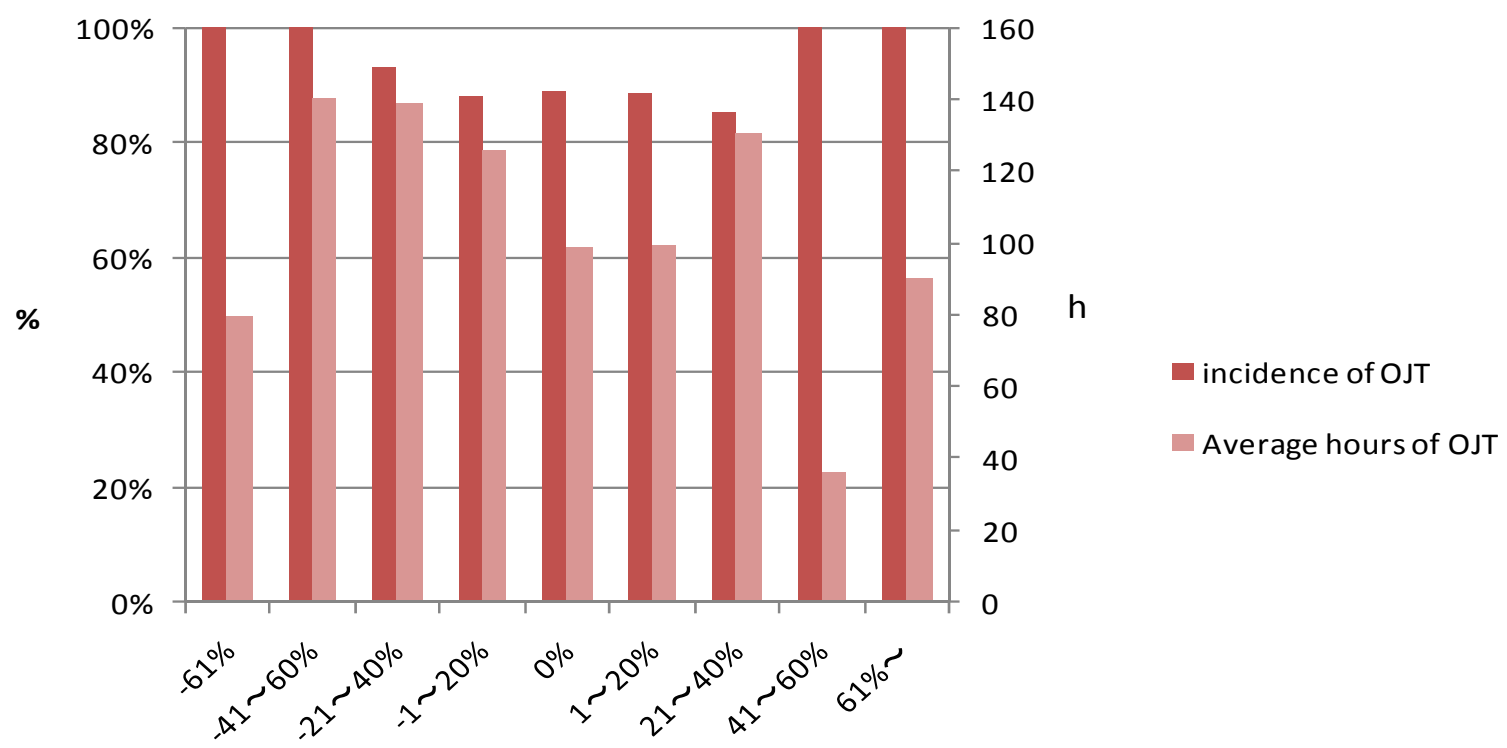

Test for difference $=0$ : Incidence of OJT: $F(8,308)=0.59 p=0.790$, Average. Hours of OJT: $F(8$, 308) $=0.43, p=0.905$ 
Figure 8: Incidence and average hours of job training by the timing of relocation across teams

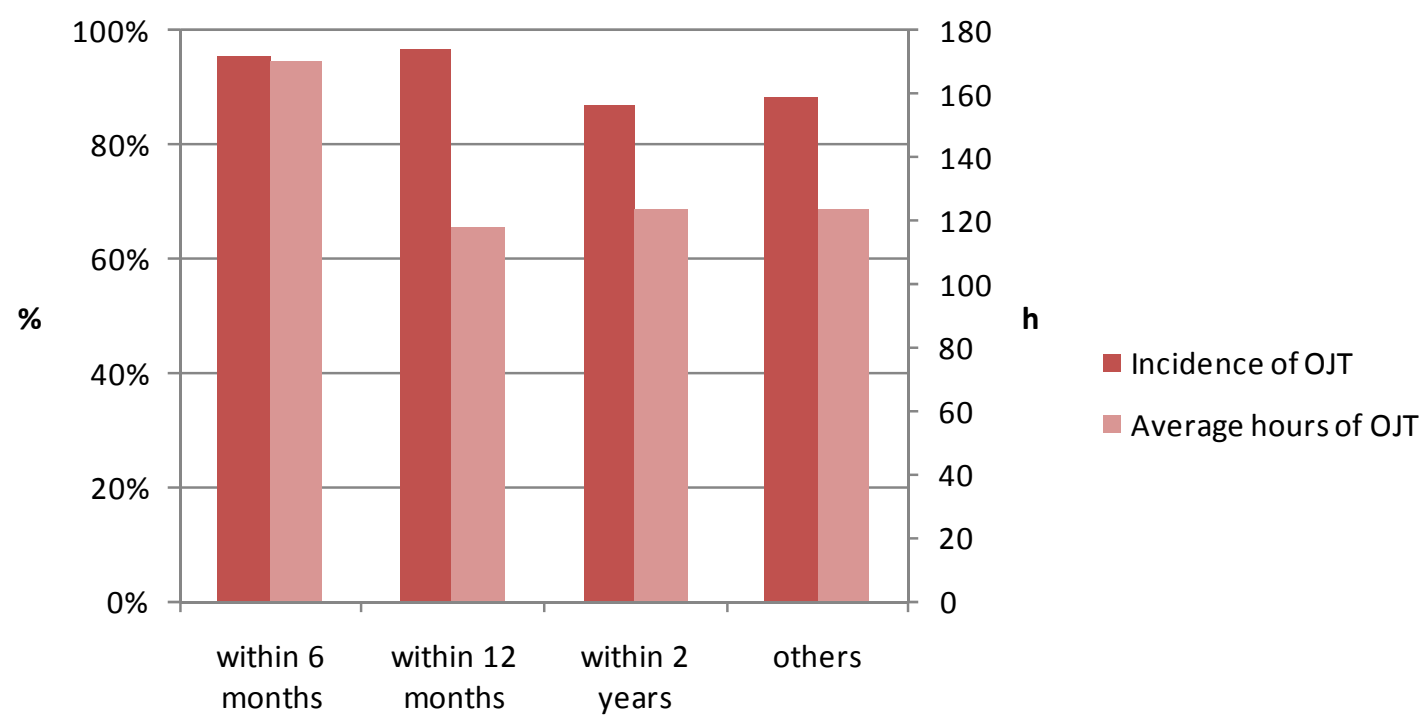

Test for difference $=0$ : Incidence of OJT: $F(3,689)=3.32, p=0.019$, Average hours of OJT: $F(3$, $685)=3.13 p=0.025$

Figure 9: Incidence and average hours of job training by productivity improvement

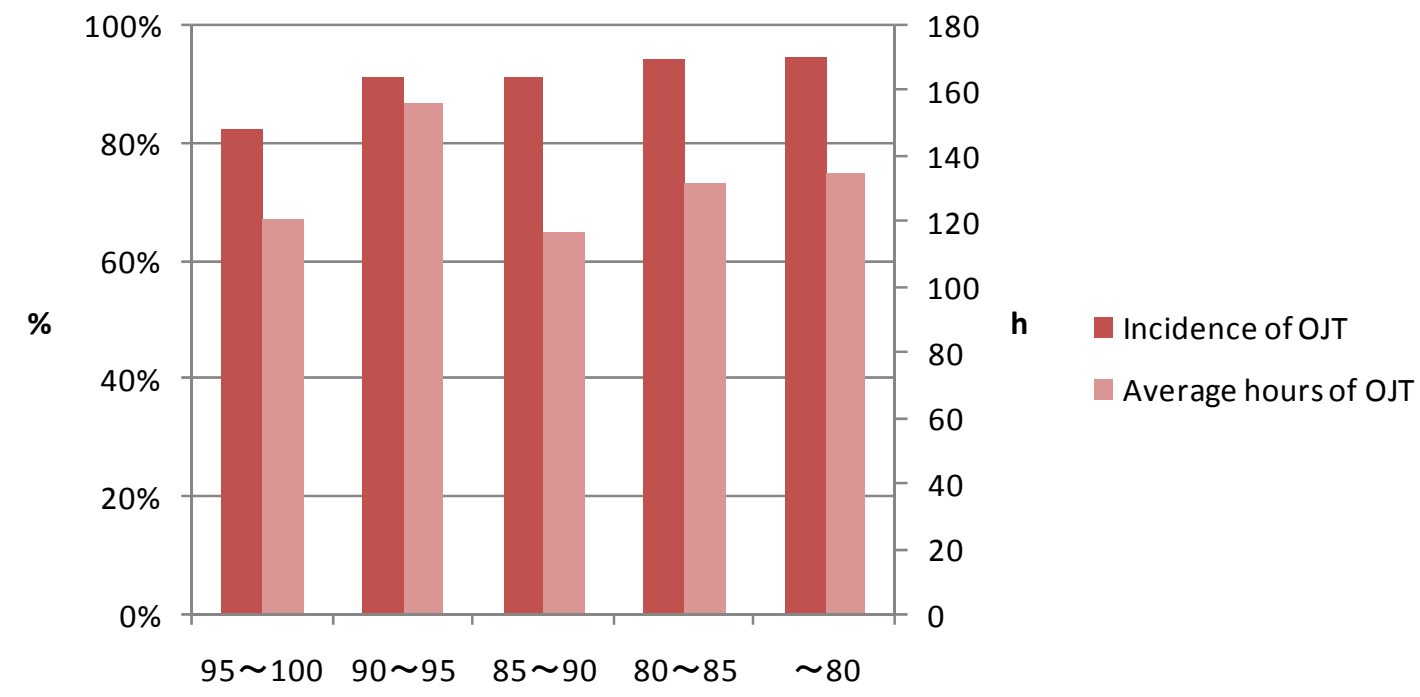

The horizontal categories represent productivity level a year ago, assuming that the current productivity is 100 . Test for difference $=0$ : Incidence of OJT: $F(4,675)=3.90, p=0.004$, Average hours of OJT: $F(4,671)=1.28, p=0.276$ 
Figure 10: Improvement of productivity and an increase in operational tasks by one-year lagged incidence of training

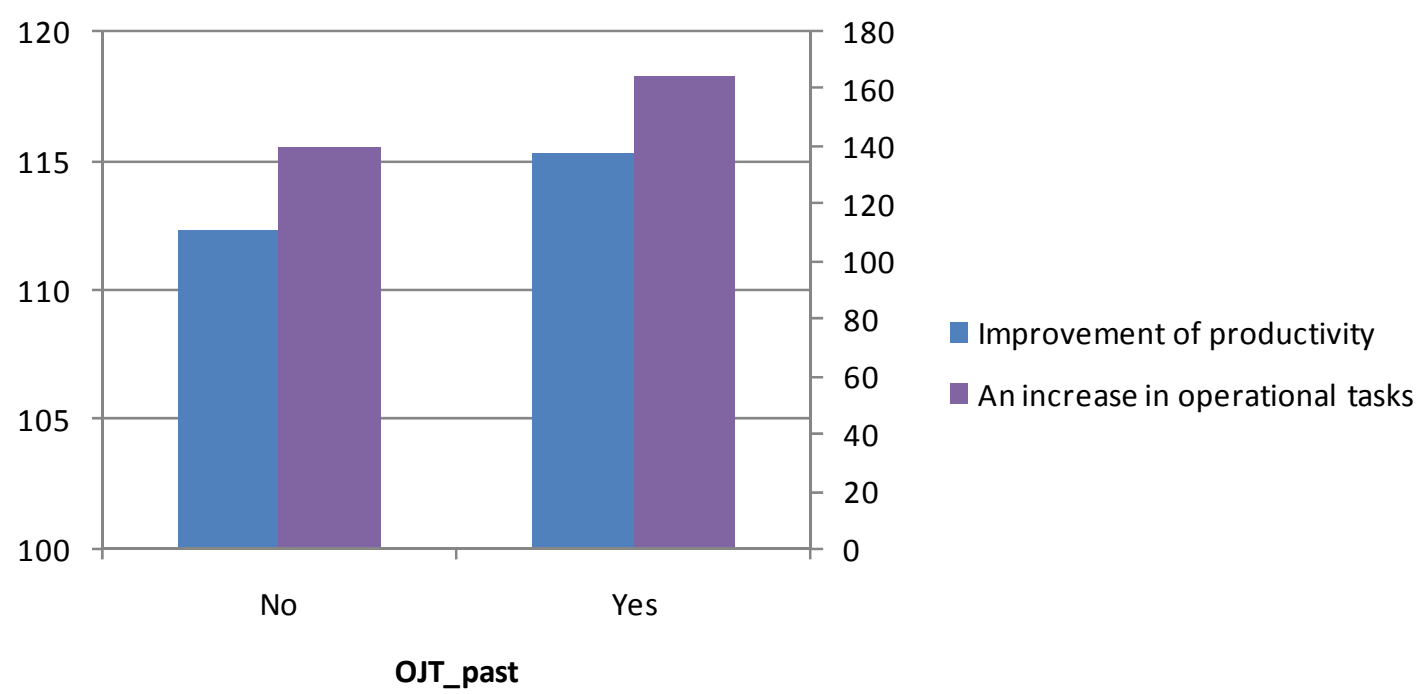

The left vertical axis represents the current productivity level, assuming that productivity level of a year ago is 100 , while the right vertical axis indicates the number of operational tasks that one can currently perform, assuming that its number of a year ago is normalized 100 . Test for difference $=0$ : Improvement of productivity: $\mathrm{t}(307)=-2.436, \mathrm{p}=0.015$, An increase in operational tasks: $\mathrm{t}(69)=$ $-0.929, \mathrm{p}=0.356$

Figure 11: Incidence and average hours of job training by an increase in operational tasks $(100=$ no change in the number of operational tasks)

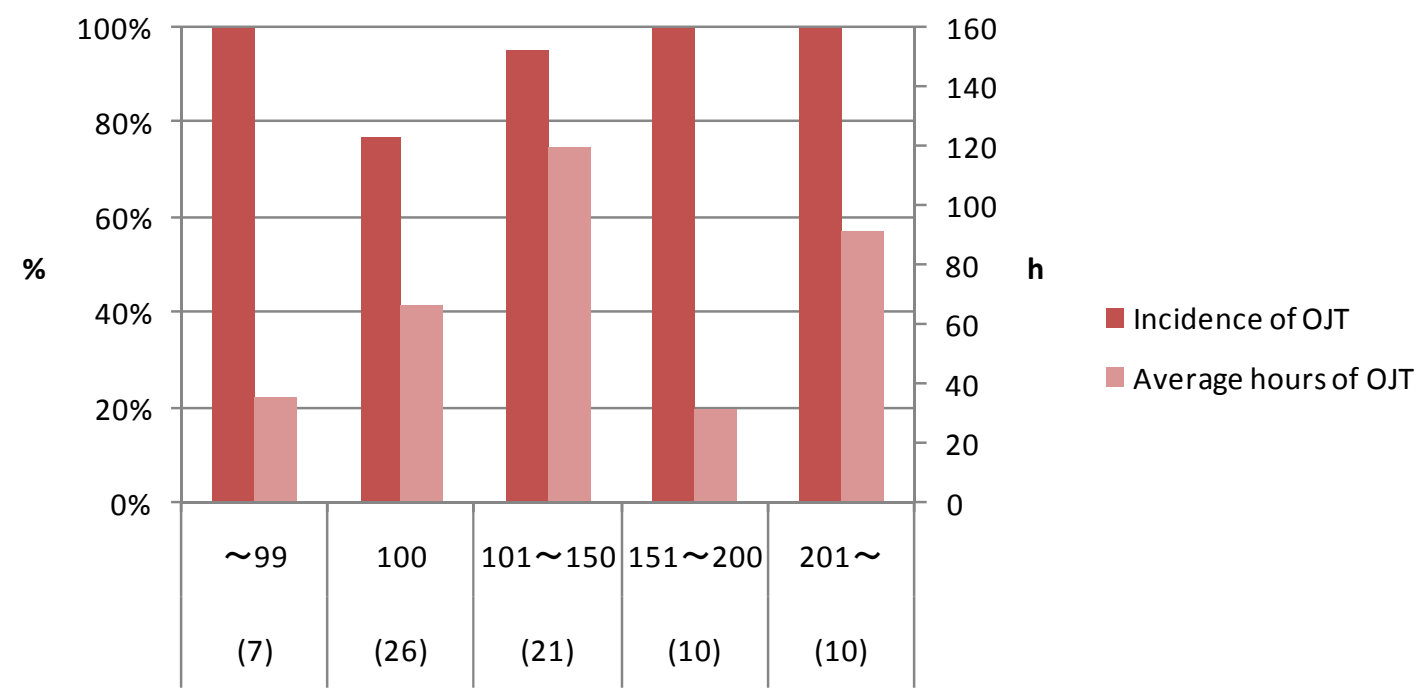

The horizontal axis indicates categories of the number of operational tasks that one can currently perform, assuming that its number of a year ago is normalized 100 . Test for difference $=0$ : Incidence of OJT : $F(4,69)=2.39, p=0.059$, Average hours of OJT: $F(4,69)=0.96, p=0.437$ 


\section{Appendix: Definitions of Variables}

\begin{tabular}{|c|c|}
\hline \multicolumn{2}{|l|}{ Variables } \\
\hline \multirow{2}{*}{ rotation } & change in rotation conducted to foremen, -1 (decrease) 0 (unchanged) \\
\hline & 1(increase) \\
\hline rotation2 & change in rotation conducted to foremen, 0 (decrease or unchanged) \\
\hline & 1 (increase) \\
\hline exp_gr & team-average years assigned in the current team \\
\hline exp & tenure within the current team \\
\hline injury & the number of absentees in a team, -1 (decrease) 0 (same) 1(increase) \\
\hline workload & the burden of workload in a team, -1(decrease) 0 (same) 1(increase) \\
\hline speed & assembly line speed in a team, -1 (decrease) 0 (same) 1(increase) \\
\hline kaizen_in & the kizen draft proposed within the team raises efficiency $=1$ \\
\hline kaizen_out & the kizen draft proposed from outside of the team raises efficiency $=1$ \\
\hline d_change_qc & change in the way conducting the Quality Control circle $=1$ \\
\hline allp & the number of operation processes in own team \\
\hline allpdiff & a change in the number of operation processes in own team \\
\hline tenure & Tenure within the firm \\
\hline skill & skill level \\
\hline d_hs & education level, high school or above=1 \\
\hline ojt & dummy indicating whether to receive OJT in the conducted month=1 \\
\hline ojt12 & OJT hours in the past one year \\
\hline ojt_within & team-average of the dummy indicating whether to receive OJT, except \\
\hline & a person self \\
\hline ojt_all & $\begin{array}{l}\text { all sampled average of the dummy indicating whether to receive OJT, } \\
\text { except a person self }\end{array}$ \\
\hline ojt12_within & team-average of OJT hours, except a person self \\
\hline ojt12_all & all sampled average of OJT hours, except a person self \\
\hline $\mathrm{rr}$ & improvement in productivity from a subjective viewpoint \\
\hline rr_past & $\begin{array}{l}\text { improvement in productivity from a subjective viewpoint in the past } \\
\text { year }\end{array}$ \\
\hline rr_within & $\begin{array}{l}\text { team-average improvement in productivity from a subjective } \\
\text { viewpoint }\end{array}$ \\
\hline rr_all & $\begin{array}{l}\text { all sample average improvement in productivity from a subjective } \\
\text { viewpoint }\end{array}$ \\
\hline oaskl_gr & a change in the number of operational tasks from Firm B \\
\hline d_firma & Dummy indicating Firm $\mathrm{A}=1$ and Firm $\mathrm{B}=0$. \\
\hline
\end{tabular}

Variable_past represents one-year lagged one of each variable. 
Appendix: Descriptive Statistics

\begin{tabular}{lrrr}
\hline \multicolumn{1}{c}{ variables } & N & \multicolumn{1}{c}{ mean } & \multicolumn{1}{c}{ SD } \\
\hline rotation & 577 & 0.414 & 0.637 \\
expchange_gr & 712 & 0.261 & 0.258 \\
exp_gr & 709 & 5.248 & 2.973 \\
exp & 688 & 5.252 & 5.423 \\
injury & 566 & 0.095 & 0.566 \\
workload & 578 & 0.452 & 0.652 \\
speed & 566 & -0.012 & 0.895 \\
kaizen_in & 555 & 0.879 & 0.326 \\
kaizen_out & 557 & 0.388 & 0.488 \\
d_change_qc & 566 & 0.214 & 0.410 \\
allp & 592 & 18.409 & 6.017 \\
allpdiff & 342 & 0.750 & 6.044 \\
pr & 574 & 39.282 & 30.597 \\
prdiff & 320 & 2.515 & 26.723 \\
tenure & 700 & 13.537 & 7.378 \\
skill2 & 691 & 1.754 & 0.692 \\
d_hs & 700 & 0.937 & 0.243 \\
ojt & 693 & 0.905 & 0.294 \\
offjt & 685 & 0.488 & 0.500 \\
selfdev & 679 & 0.171 & 0.377 \\
ojt12 & 692 & 131.899 & 390.678 \\
offjt12 & 683 & 5.803 & 11.776 \\
selfdev12 & 681 & 18.273 & 80.653 \\
ojt_within & 722 & 0.906 & 0.161 \\
ojt_all & 739 & 0.905 & 0.016 \\
ojt12_within & 722 & 127.033 & 208.150 \\
ojt12_all & 739 & 130.839 & 18.992 \\
rr & 681 & 115.052 & 10.181 \\
oaskl_gr & 95 & 161.101 & 239.456 \\
\hline
\end{tabular}




\section{Appendix: Questionnaire of Assemblers}

\section{Questionnaire No.1 on Skills Development in the Workplace}

(For Employees)

September 2006

Osaka University, Institute of Social and Economic Research

Kyoto University, Institute of Economic Research

[Request for cooperation in the questionnaire]

The purpose of this questionnaire is to survey how employees in the workplace acquire knowledge and skills required for the job, and to measure the effectiveness of these activities.

We would appreciate your taking the time from your busy schedule to answer the questionnaire with your frank opinions. This questionnaire will be conducted 3 times in the coming 12 months. This is the first of the three questionnaires. (Questionnaire No.2 scheduled in Feb. 2007, No.3 in July 2007)

The details of your answers will be statistically processed, and please be assured that personal information entered in this questionnaire will $\underline{\text { NOT }}$ be disclosed whatsoever.

[Instructions for completing the questionnaire]

Please follow the instructions given for each question, such as circle the number that applies.

When you finish completing the questionnaire, please submit it in the attached envelope.

※ If you have any questions, please contact: Personnel Dept. (Direct) XXX-XXXX 
Please tell us about yourself.

Q1. When did you graduate from your last school?

In 19

Q2. In the system to acquire specialized technical skills, what is your level of certification?
1. Level S
2. Level A
3. Level B
4. Level C
5. Not certified

Q3. Is there anyone in your family (parents, brother/sister, child, etc) who has worked for (or is working for) this company? (Circle one answer)
1. Yes
2. No

These are questions on how you acquire knowledge and skills required for the job.

Q4. When you are in the workplace and a senior staff or colleague teaches you how to do the job while actually showing it to you, or learning by looking at how others work or referring to work manuals is called On-the-Job Training (OJT). How many hours of On-the-Job Training did you experience in the past month? If you did not receive any training, fill in zero (0).

Calculation example: An entire day of OJT is $8 \mathrm{hrs}$

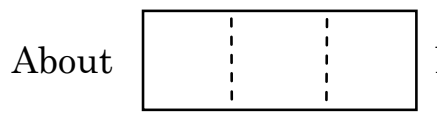
hours last month

Q5. What percent of On-the-Job Training that you received last month was hours taught by a supervisor, senior worker or colleague? (Circle one choice)
1. $0 \sim 30 \%$ (Mimimal)
2. $40 \sim 50 \%$ (About half)
3. $60 \sim 70 \%$ (More than half)
4. $80 \sim 100 \%$ (Almost all)

Q6. Looking at the situation in the past 6 months, was there more On-the-job Training than usual or less training than usual last month? (Circle one choice)

1. More than twice the average in the past 6 months

2. 1.5 times the average in the past 6 months

3. The same amount as in the past 6 months

4. About half the average in the past 6 months

5. Less than half the average in the past 6 months

Q7. Was the On-the-Job Training conducted last month mainly in response to your request, or did a supervisor give instructions to conduct the training? (Circle one choice)
1. I requested the training
2. The supervisor instructed the training

Q8. Which of the following applies to the On-the-Job Training conducted last month? (Circle one choice)

1. It was training to make up for lack of skill/knowledge

2. It was training was to acquire higher skills 
Q9. Did you receive Off-the-Job Training (Off-JT) in the past 6 months? Off-the-Job Training is group seminars or training conducted away from the production line.
1. Yes $\downarrow$
2. No $\rightarrow \rightarrow$ Skip to Q12

\section{Go to Q10}

Q10. In the past 6 months, how many times did you experience Off-the-Job Training (Off-JT), and in average how long did each Off-JT last? (Circle one choice)
Number of times:
1. 1 time
2. 2 times
3. 3 times
4. 4 times
5. Between 5 and 9 times
6. More than 10 times

Average duration for each Off-JT:

1. Less than 30 min.

2. $30 \mathrm{~min}$. to less than $60 \mathrm{~min}$. 3. $60 \mathrm{~min}$. to less than $90 \mathrm{~min}$.
4. $90 \mathrm{~min}$. to less than 2 hours
5. 2 hours to less than 3 hours
6. More than 3 hours

Q11. Which of the following applies to the Off-the-Job Training conducted in the past 6 months?

(Circle one choice)

1. It was training to make up for lack of skill/knowledge

2. It was training was to acquire higher skills

Q12. In the past 6 months, did you do any studying on you own (Self Development) for your present job or for a job that you want to do in the future?

※ “Self Development” is study done during off duty hours by reading books or textbooks, or taking classes at vocational schools or colleges, or studying by correspondence. (This does not include hobbies unrelated to your work, leisure, sports, or health maintenance or promotion activities)
1. Yes $\downarrow$
2. No $\rightarrow \rightarrow$ Skip to Q14
Go to Q13

Q13. What is the frequency and average duration of each Self Development study in the past 6 months?

Additional Q13-2 Is the skill/knowledge that you acquired through Self Development study in the past 6 months useful only for your current job? Or do you think that it would also be useful for a similar type of job at another company? Choose one reply from the 5 items below and circle the number.

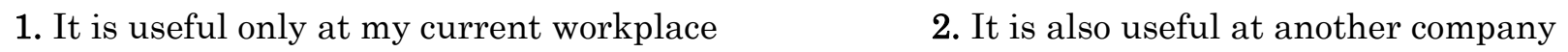

3. It is not useful at my current workplace or another company

4. It is not useful immediately at my current workplace or another company, but it will broaden my abilities as a professional in the long term

Q14. Circle all that apply to your day-to-day life in the past month. 

1. Busy but fulfilling
2. Frankly speaking, a bit overworked
3. Enjoyed the days off
4. Exercised regularly
5. Refrained from drinking alcohol
6. Stopped smoking

These are questions on your job and how you work in your current and past workplaces.

Q15. How long have you belonged to the current Kumi (team)?

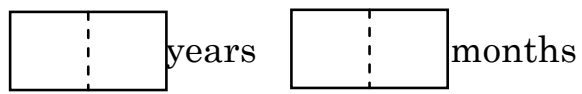

Q16 Assuming that your current work proficiency is 100 and that your productivity immediately after you joined the company and assigned to a workplace was zero, what do you think your proficiency level was 6 months ago and 1 year ago? Choose one reply from the 5 choices below and circle the number.
(1) Proficiency 6 months ago $\cdots 1.95 \sim 100$
2. $90 \sim 95$
3. $85 \sim 90$
4. $80 \sim 85$
5. Less than 80
(2) Proficiency 1 year ago $\cdots \cdots \cdot 1.95 \sim 100$
2. $90 \sim 95$
3. $85 \sim 90$
4. $80 \sim 85$
5. Less than 80

Q17. This is a question for those who have worked in the current workplace for more than one year. What was your proficiency level immediately after being assigned to the current workplace? This is assuming that your current work proficiency is 100 and that your productivity immediately after you joined the company and assigned to a workplace was zero. Choose one reply from the 5 choices below and circle the number.
1. $90 \sim 100$
2. $80 \sim 90$
3. $70 \sim 80$
4. $60 \sim 70$
5. Less than 60

Q18. Of all processes in your workplace, how many processes are you fully capable of doing?

Confirm with $\mathrm{GL}$ and fill in the total number of processes

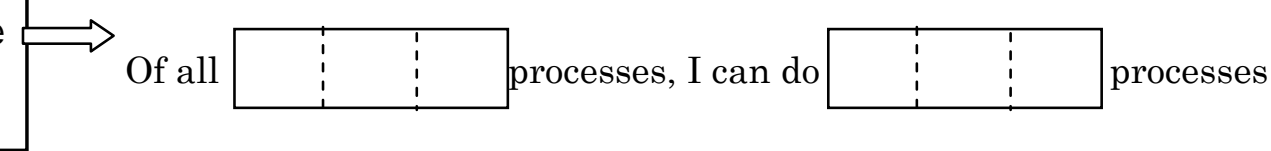

Q19. In the past month, how many Kaizen improvement or creative proposals did you submit? Of these proposals, how many were actually adopted?

Total number of proposals , of which

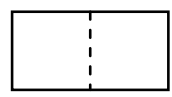
proposals were adopted

Q20. How well do the following items describe your direct supervisor (GL or CL) in the workplace? Check the number that best describes each item.

\begin{tabular}{|l|c|c|c|c|c|}
\hline & $\begin{array}{l}\text { Does not } \\
\text { describe } \\
\text { the person }\end{array}$ & $\begin{array}{l}\text { Somewhat } \\
\text { does not } \\
\text { describe }\end{array}$ & Neither & $\begin{array}{l}\text { Somewhat } \\
\text { describes }\end{array}$ & $\begin{array}{c}\text { Describes } \\
\text { the person }\end{array}$ \\
\hline 1. Work plans and allocations are done properly & 1 & 2 & 3 & 4 & 5 \\
\hline $\begin{array}{l}\text { 2. Properly voices what needs to be said to department } \\
\text { and section leaders and relevant departments }\end{array}$ & 1 & 2 & 3 & 4 & 5 \\
\hline 3. Makes fair evaluations & 1 & 2 & 3 & 4 & 5 \\
\hline $\begin{array}{l}\text { 4. Really understands the subordinate's worries and } \\
\text { complaints }\end{array}$ & 1 & 2 & 3 & 4 & 5 \\
\hline 5. Friendly and easy to talk to & 1 & 2 & 3 & 4 & 5 \\
\hline
\end{tabular}




\begin{tabular}{|l|c|c|c|c|c|}
\hline $\begin{array}{l}\text { 6. Is a competent supervisor compared to the } \\
\text { predecessor }\end{array}$ & 1 & 2 & 3 & 4 & 5 \\
\hline $\begin{array}{l}\text { 7. Allows workers to actively experience many } \\
\text { processes }\end{array}$ & 1 & 2 & 3 & 4 & 5 \\
\hline
\end{tabular}

Q21. How well do the following items describe your workplace? Check the number that best describes each item.

\begin{tabular}{|l|c|c|c|c|c|}
\hline & $\begin{array}{l}\text { Does not } \\
\text { describe my } \\
\text { workplace }\end{array}$ & $\begin{array}{l}\text { Somewhat } \\
\text { does not } \\
\text { describe }\end{array}$ & $\begin{array}{l}\text { Neither } \\
\text { 1. The womewhat } \\
\text { describes }\end{array}$ & $\begin{array}{l}\text { Describes } \\
\text { my workplace }\end{array}$ \\
\hline $\begin{array}{l}\text { 2. Information that needs to be shared by everyone is } \\
\text { well communicated in the workplace }\end{array}$ & 1 & 2 & 3 & 4 & 5 \\
\hline $\begin{array}{l}\text { 3. There is an atmosphere to help others even if it does } \\
\text { not concern your own task }\end{array}$ & 1 & 2 & 3 & 4 & 5 \\
\hline $\begin{array}{l}\text { 4. Meetings are conducted in an efficient and active } \\
\text { manner }\end{array}$ & 1 & 2 & 3 & 4 & 5 \\
\hline $\begin{array}{l}\text { 5. Roles and responsibilities of each member is clear } \\
\text { and controlled }\end{array}$ & 1 & 2 & 3 & 4 & 5 \\
\hline $\begin{array}{l}\text { 6. The supervisor instructs and trains each member } \\
\text { according to his/her characteristic }\end{array}$ & 1 & 2 & 3 & 4 & 5 \\
\hline $\begin{array}{l}\text { 7. The workplace is not active and the mood tends to be } \\
\text { depressing }\end{array}$ & 1 & 2 & 3 & 4 & 5 \\
\hline
\end{tabular}

* This is the end of the questionnaire. Thank you very much for your cooperation. 


\section{Appendix: Questionnaire of Foremen}

\section{Questionnaire No.1 on Skills Development in the Workplace}

(For Supervisors)

September 2006

Osaka University, Institute of Social and Economic Research

Kyoto University, Institute of Economic Research

[Request for cooperation in the questionnaire]

The purpose of this questionnaire is to survey how employees in the workplace acquire knowledge and skills required for the job, and to measure the effectiveness of these activities.

We would appreciate your taking the time from your busy schedule to answer the questionnaire with your frank opinions. This questionnaire will be conducted 3 times in the coming 12 months. This is the first of the three questionnaires. (Questionnaire No.2 scheduled in Feb. 2007, No.3 in July 2007)

The details of your answers will be statistically processed, and please be assured that personal

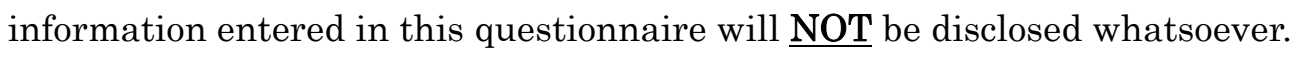

[Instructions for completing the questionnaire]

Please follow the instructions given for each question, such as circle the number that applies.

When you finish completing the questionnaire, please submit it in the attached envelope.

※ If you have any questions, please contact: Personnel Dept. (Direct) XXX-XXXX 
Please tell us about your workplace. "Workplace" here refers to the Kumi (team).

Q1. Which of the category best describes the attitude in your workplace for each item below? Circle the number that applies.

\begin{tabular}{|l|l|l|l|l|}
\hline & $\begin{array}{l}\text { Does not } \\
\text { describe } \\
\text { workplace }\end{array}$ & $\begin{array}{l}\text { Somewhat does } \\
\text { not describe }\end{array}$ & Neither & $\begin{array}{l}\text { Somewhat } \\
\text { describes }\end{array}$ \\
\hline $\begin{array}{l}\text { (1) Asks employees to work according to instructions } \\
\text { rather than to think on their own and take action } \\
\text { on their own. }\end{array}$ & 1 & 2 & 3 & 5 \\
\hline $\begin{array}{l}\text { (2) Personnel allocation emphasizes putting the } \\
\text { right person in the right place at that time, } \\
\text { rather than on a long-term perspective to develop } \\
\text { human resources. }\end{array}$ & 1 & 2 & 3 & 4 \\
\hline
\end{tabular}

Q2. Circle all items that apply to your workplace.

1. We have daily morning meetings

3. There are frequent rotations
2. Hot time meetings are held daily

4. Fixed-term employees are often hired (as full-time employees)

Q3. When was the last time a large-scale investment was made in the production line in your workplace?

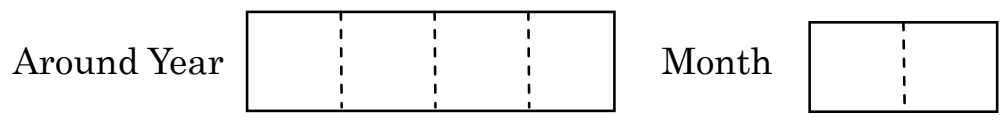

Q4. The following are questions on how long it takes to become proficient in the work processes in your workplace.

(1) How many processes do you have in your workplace?

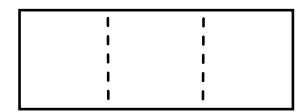

(2) How long does it take for an average high school graduate to become proficient in all process in your workplace?

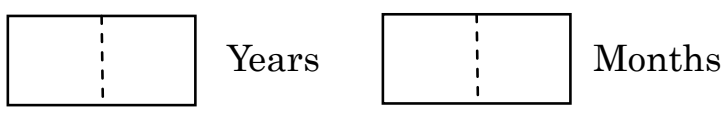

Q5. Please tell us about the $\mathrm{QC}$ circle meetings held in your workplace in the past 6 months. What are the frequency and average duration of each meeting?

(1)

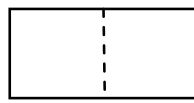
times a month

(2) Average duration per meeting is about

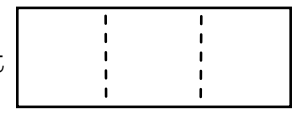
$\operatorname{hours}(\mathrm{s})$

Q6. Has there been any changes described below in your workplace in the past 12 months? Check the item that applies. 


\begin{tabular}{|c|c|c|}
\hline & Compared to 6 months ago & Compared to 12 months ago \\
\hline $\begin{array}{l}\text { 1. Changes in the total number of } \\
\text { people in the workplace }\end{array}$ & 1 Increased 2 Same 3 Decreased & 1 Increased 2 Same 3 Decreased \\
\hline 2. Turnover of talented people & 1 Left 2 None 3 Joined & 1 Left 2 None \\
\hline $\begin{array}{l}\text { 3. Changes in the number of rotation } \\
\text { opportunities }\end{array}$ & 1 Increased 2 Same 3 Decreased & 1 Increased 2 No change 3 Decreased \\
\hline $\begin{array}{l}\text { 4. Changes in the workload in the } \\
\text { entire workplace }\end{array}$ & 1 Increased 2 Same 3 Decreased & 1 Increased 2 Same 3 Decreased \\
\hline $\begin{array}{l}\text { 5. Revisions in the workplace } \\
\text { target/index (i.e. changed to } \\
\text { emphasize cost and safety instead of } \\
\text { efficiency) }\end{array}$ & 1 Target was revised 2 No change & 1 Target was revised $\mathbf{2}$ No change \\
\hline $\begin{array}{l}\text { 6. Orders from upper management to } \\
\text { change the direction of human } \\
\text { resource development in the } \\
\text { workplace }\end{array}$ & $\begin{array}{l}1 \text { There were orders to make changes } \\
2 \text { No change }\end{array}$ & $\begin{array}{l}1 \text { There were orders to make changes } \\
2 \text { No change }\end{array}$ \\
\hline 7. Changes in the line speed & 1 Faster 2 Same $\mathbf{3}$ Slower & 1 Faster 2 Same 3 Slower \\
\hline $\begin{array}{l}\text { 8. Someone in the workplace fell sick or } \\
\text { was injured }\end{array}$ & 1 Yes & 1 Yes \\
\hline $\begin{array}{l}\text { 9. Kaizen improvement proposals from } \\
\text { the workplace were adopted and the } \\
\text { work was made easier }\end{array}$ & 1 Yes & 1 Yes \\
\hline $\begin{array}{l}\text { 10. Kaizen improvement proposals from } \\
\text { outside the workplace were adopted } \\
\text { and the work was made easier }\end{array}$ & 1 Yes & 1 Yes \\
\hline $\begin{array}{l}\text { 11. Revisions were made in the } \\
\text { personnel allocation }\end{array}$ & 1 Yes & 1 Yes \\
\hline 12. The work steps were changed & 1 Yes & 1 Yes \\
\hline $\begin{array}{l}\text { 13. Operation methods for the } \mathrm{QC} \text { circle } \\
\text { were changed }\end{array}$ & 1 Yes & 1 Yes \\
\hline
\end{tabular}

Q7. If the productivity of your workplace 12 months ago was 100 , what do you think are the productivity levels for 6 months ago and now?

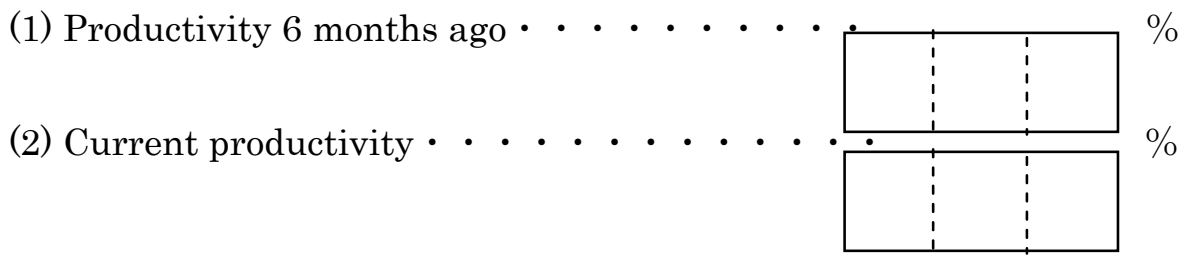

Q8. Check all items that apply to your workplace.

1. The workplace has difficulties in responding to changes in the line speed

2. There are many processes, and a long training period is required to become proficient in all of them

3. There is a variance in the proficiency among my subordinates, and work management requires my full attention

4. There are many processes that require higher skills compared to other Kumi on the same line 
5. I'm very busy and cannot find enough time to train my subordinates

6. There are many challenges, but I am fortunate to have good people and we work well together

Q9. In the past month, how many Kaizen improvement or creative proposals were submitted? Of these proposals, how many were actually adopted?

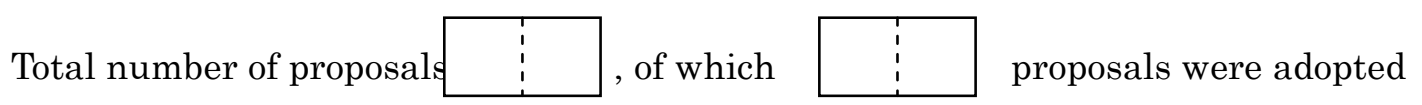

* This is the end of the questionnaire. Thank you very much for your cooperation. 